\title{
توسيط التراحم الأتي في العلاقة بين التوجيه المهني والنواتج التتظيمية بالتطبيق على معاوني أعضاء هيئة التدريس بجامعة المنصورة

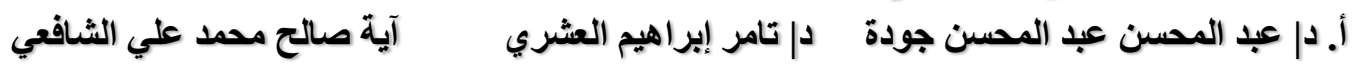

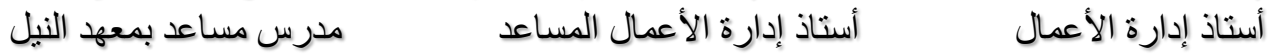

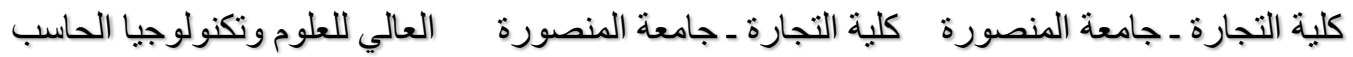

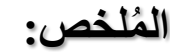

استهدفت هذه الدراسة تحديد التأثير المباشر و غير المباشر للتوجيه المهني على النواتج التتظيمية

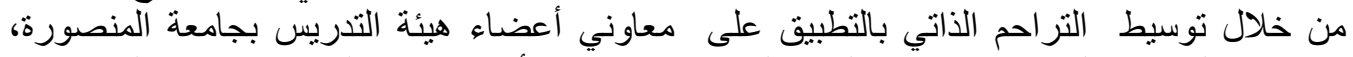

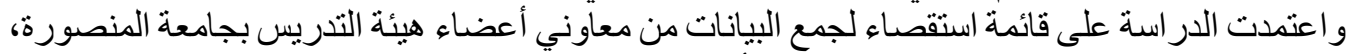

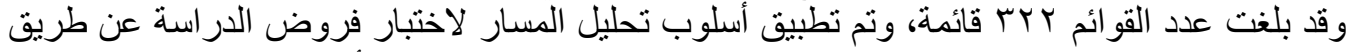

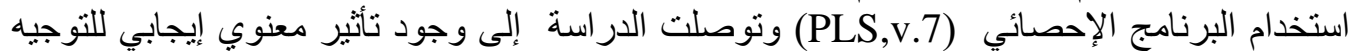

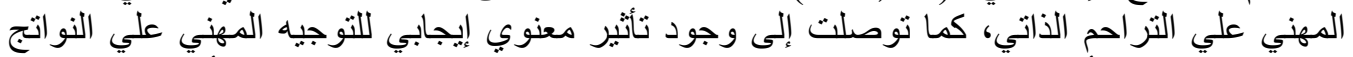

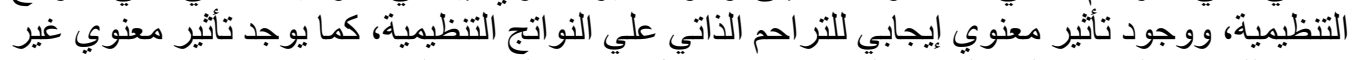

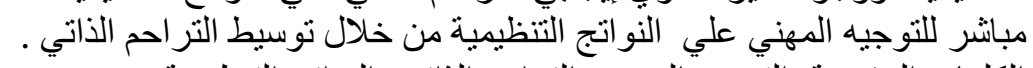
الكلمات الرئيسية: التوجيه المهني، التراحم الذاتي، النواتج التنظية تلنية.

\section{Abstract:}

This study aimed to investigate the direct and indirect effect of career mentoring on organizational outcomes through self-compassion. Data were collected 322 Teaching assistants in Mansoura university. Partial least squares structural equation modeling (PLS-SEM) was employed to test the hypotheses.

The study results showed that there were direct positive significant effects of career mentoring on self-compassion. Also, found a significant positive effect of career mentoring on organizational outcomes. And found a significant positive effect of self-compassion on organizational outcomes. Moreover, found a significant positive indirect effect of career mentoring on organizational outcomes through mediating self-compassion.

Keywords: career mentoring, self-compassion, organizational outcomes.

تو اجه الهيئة المعاونة الكثير من التحديات في مجال العمل الأكاديمي، لذلكئ يسعي إلى إلى

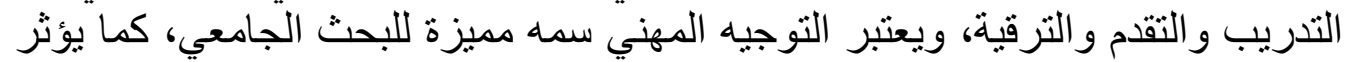

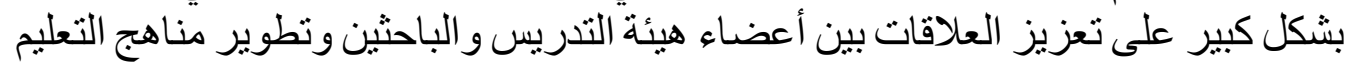

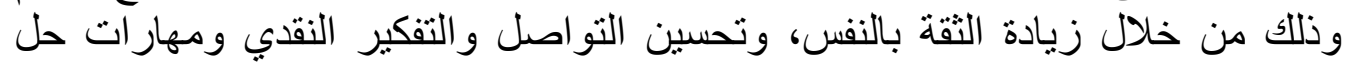

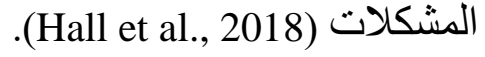




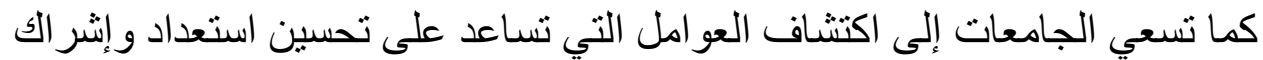

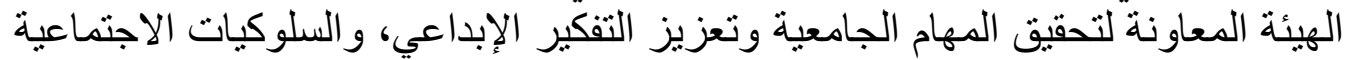

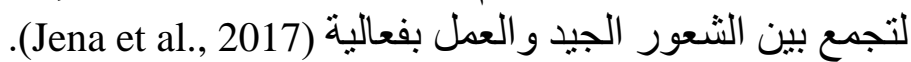

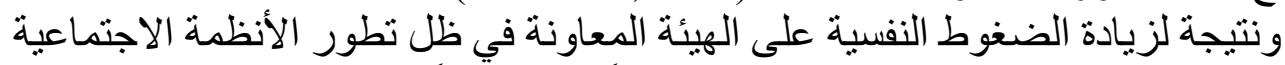

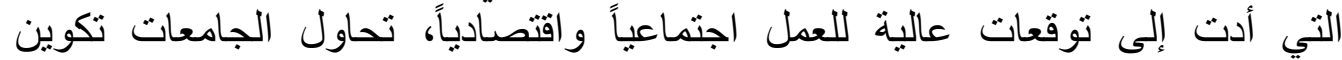

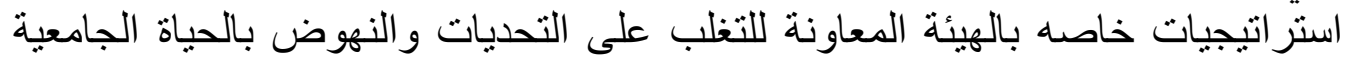

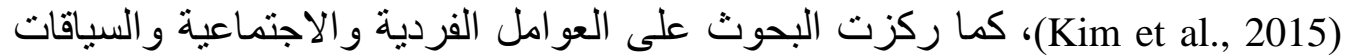

الأكاديمية التي تعوق وثُبسر سير العمل المهني (Solomon \&Barden, 2016).

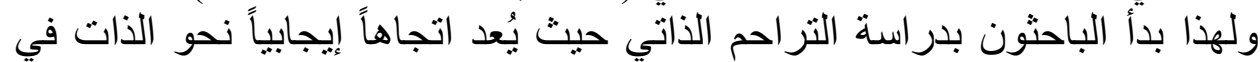

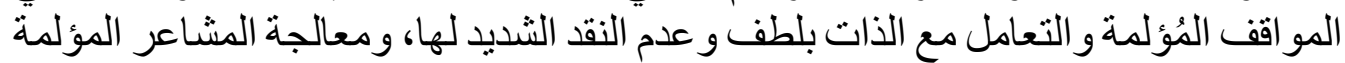
و التعامل معها بعقل متفتح (Neff, 2003a \& Neff, Knox, 2017). أولاً: الإطار النظري وبناء الفروض: أ التوجيه المهني career mentoring:

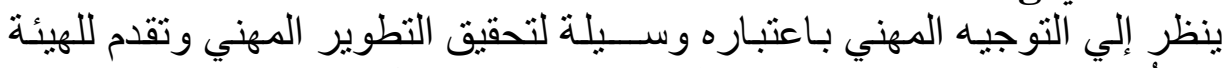

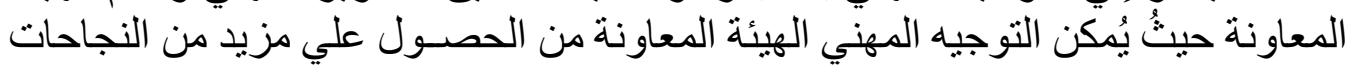

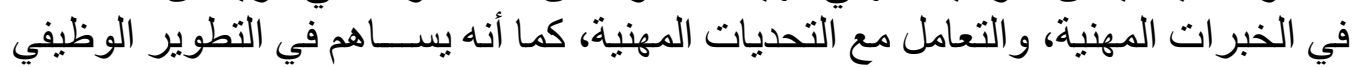

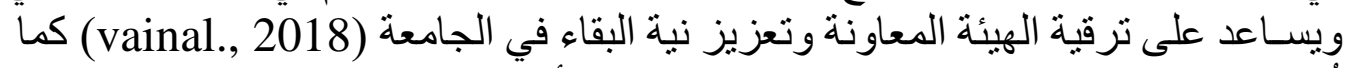

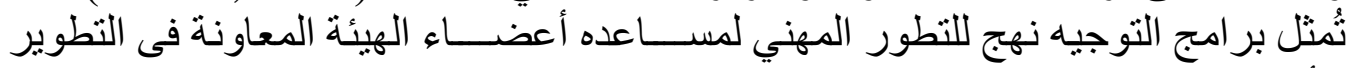
الأكاديمي وتعمل علي التوازن بين المسؤوليات الثخصية والمهنية ومتابعة المنح الدر اسية النية . (Giancola et al .,2020)

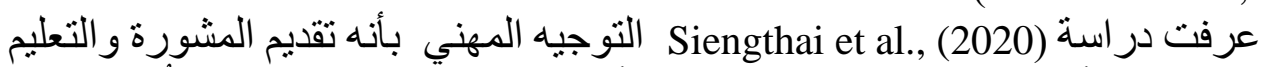

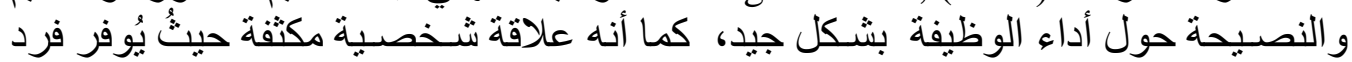

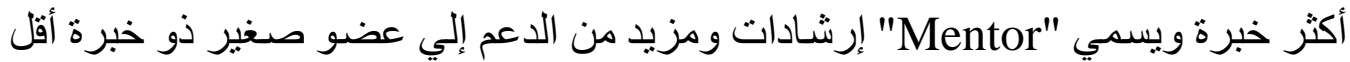

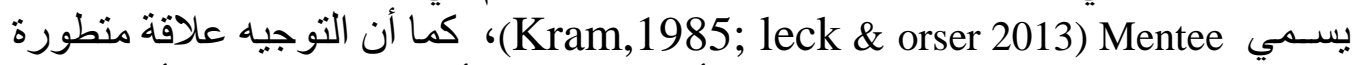
وطوعية بين الموجه و المتعلم تركز علي الأهداف طويلة الأجل والقرر اتل، كما أن التوجيه و الرعاية مهمين للترقية الموظفين في الكنظمات.

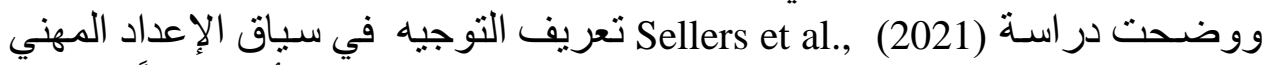

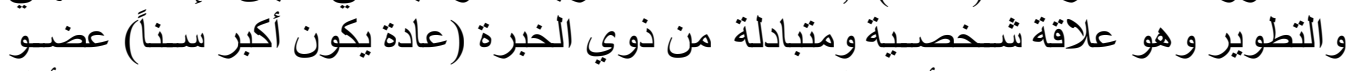

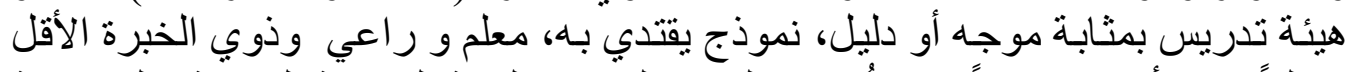

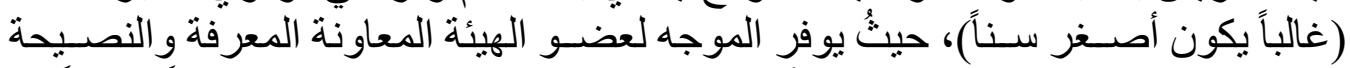

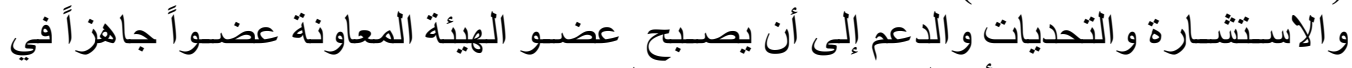

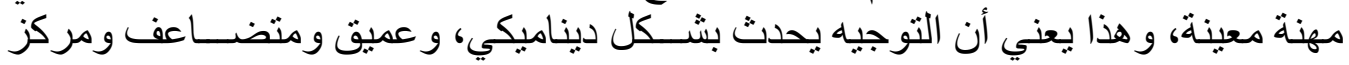

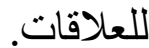


و وتبني الباحثون التعريف التالي للتوجيه المهني لأنه أكثر شمو لاً واستخداماً

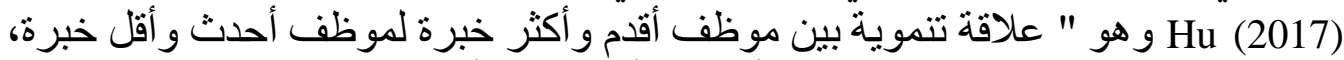

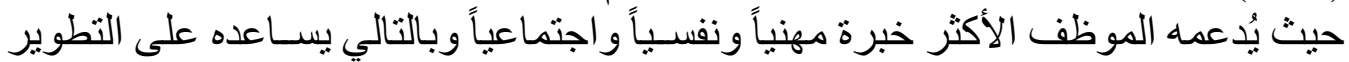

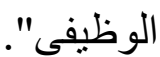

Jacobi, 1991; Kram, 1985; Noe, 1988; Ragins \& ) وركزت الدر اســات التالية (McFarlin, 1990; Coppin \& Fisher, 2020

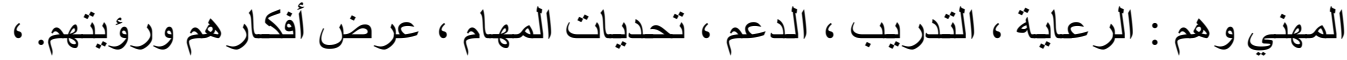

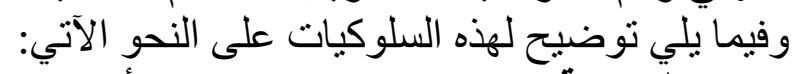

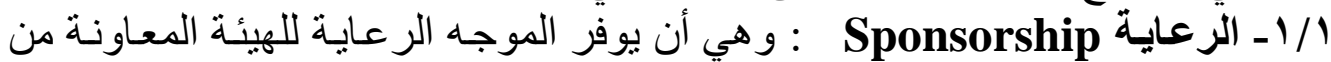

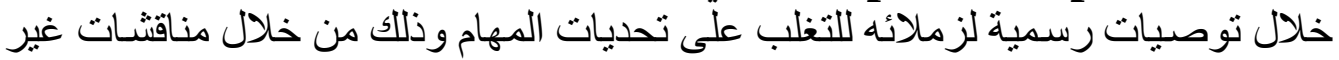

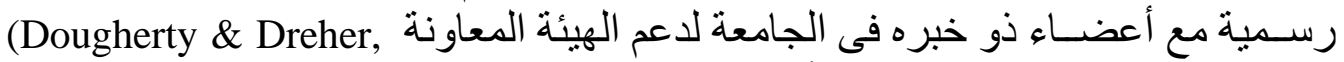
(2007 ، وتحدد الجامعة مسـتوي تأثير الموجه من خلال قدرة الموجه على تلى توفير الرعاية

للإيئة المعاونة (Coppin \& Fisher, 2020).

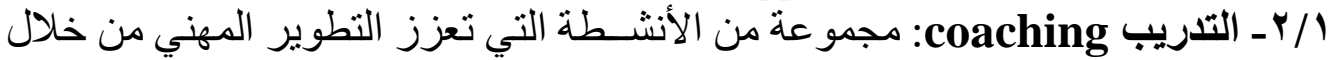

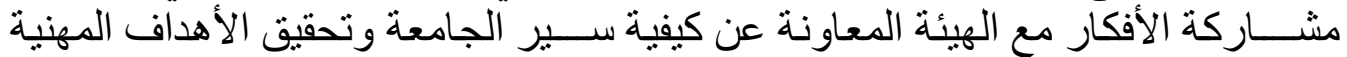

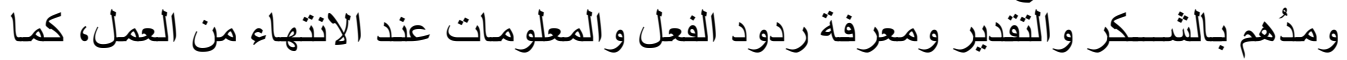

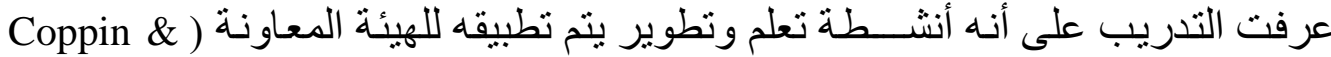

(Fisher, 2020

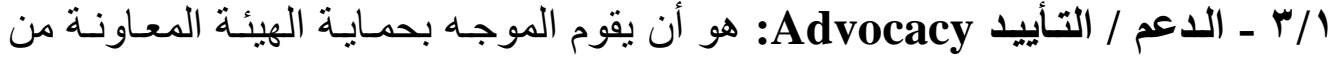

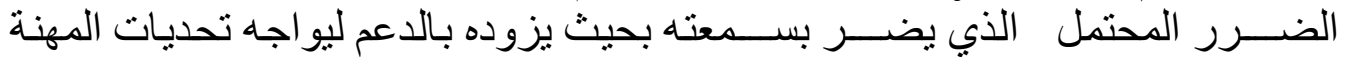
. (Coppin \& Fisher, 2020)

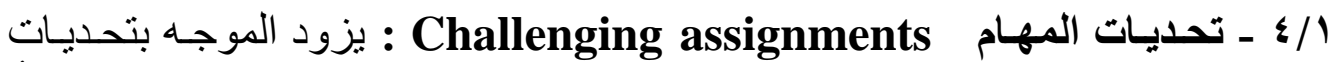

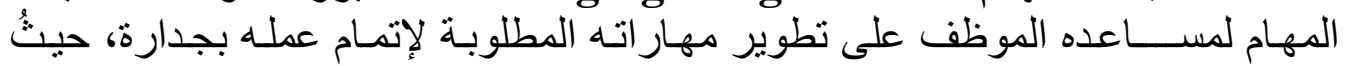

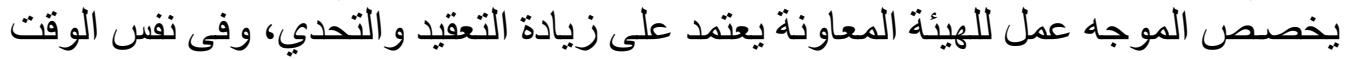

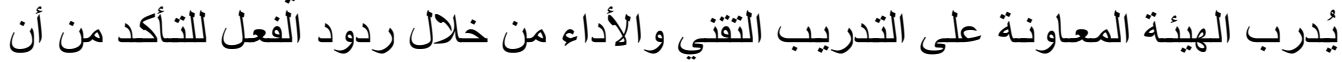

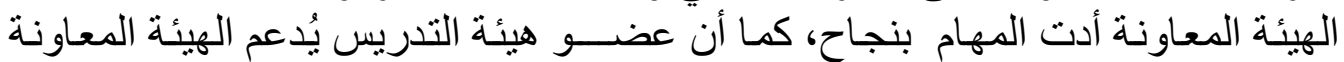

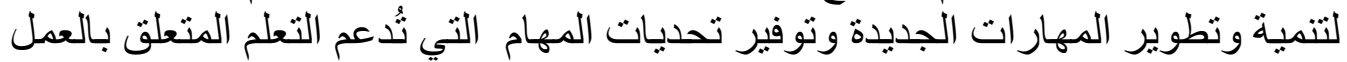
و الذي هو ضـروري للهيئة المعاونة لاســتخلال فرص مهنية فى المسـتقبل ( \&

(Fisher, 2020

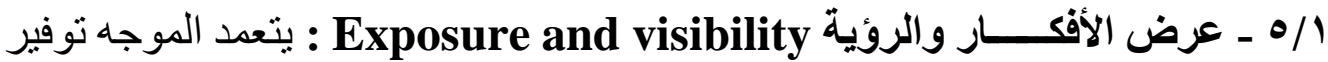

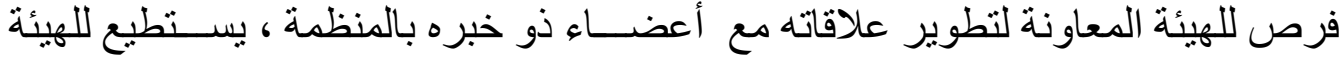

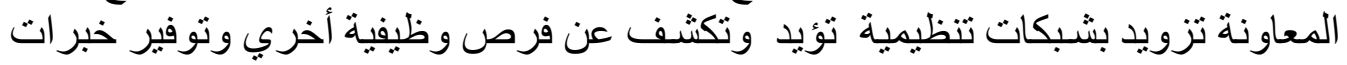




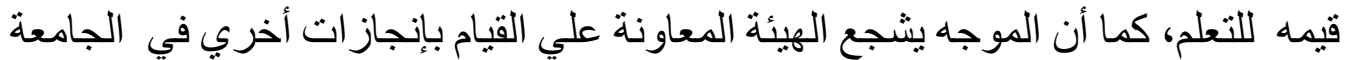

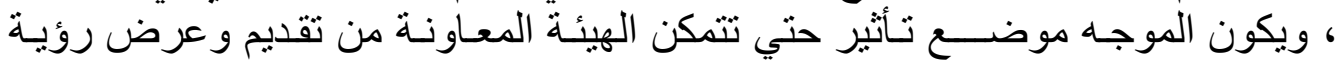

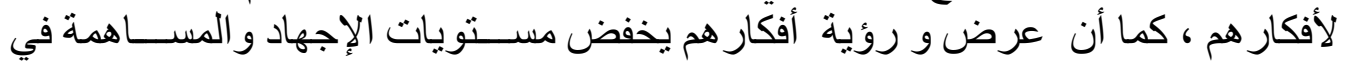

النجاح المهني(Coppin \& Fisher, 2020).

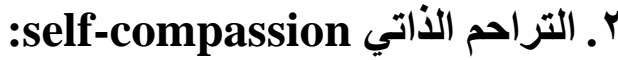

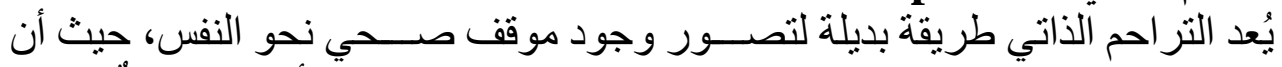

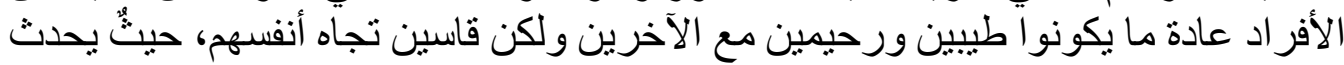

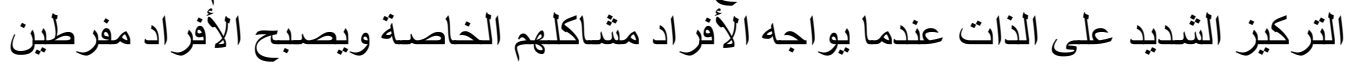

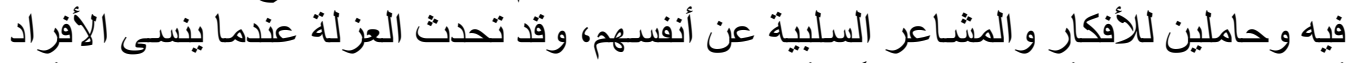

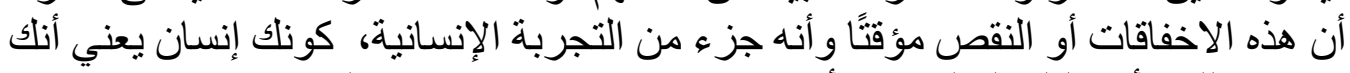

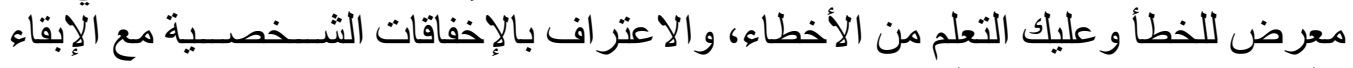
علي منظور متو ازن مع الذات (Neff \& Vonk, 2009) .

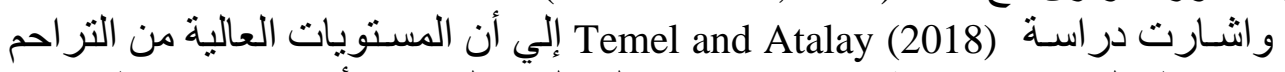

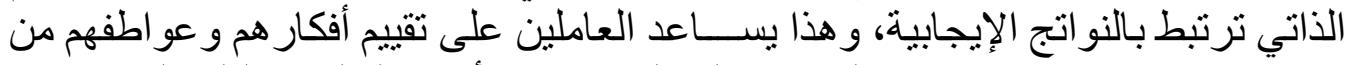

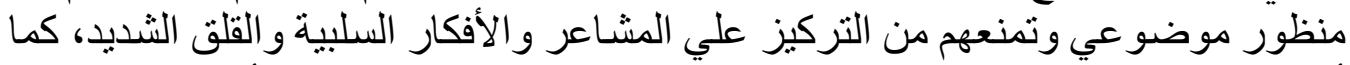

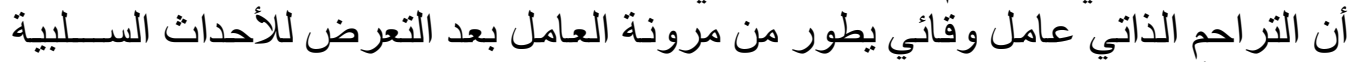

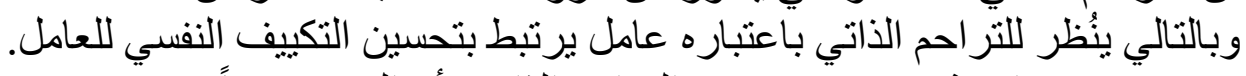

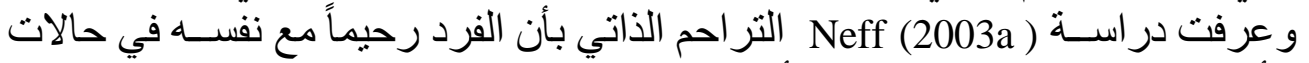

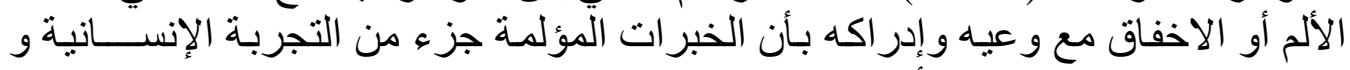

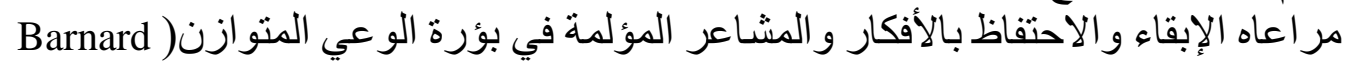

. ( \& Curry, 2011; Costa et al., 2016; Temel \& Atalay, 2018; Wu et al., 2019 كما أوضحت در اسة (2018) Phillips أن التر احم الذاتي سلوك ذاتي إيجابي يساعد

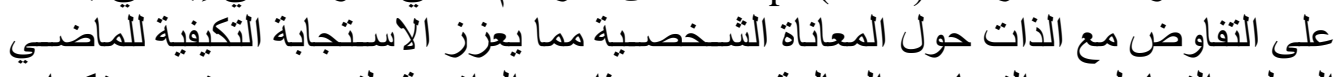

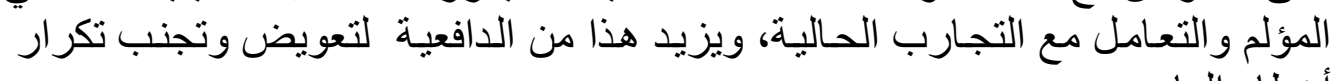
أخطاء الماضي.

كما وصـفت دراسـة Weinstock et al. التر احم الذاتي من منظور تطوري

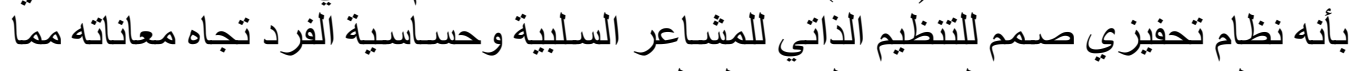
يؤدي إلي تخفيف معاناه الفرد و الالتز أ بالعمل.

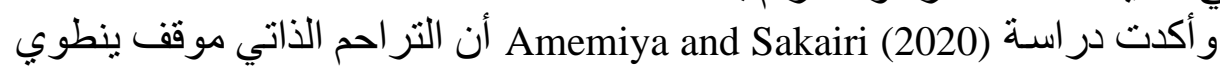
على قبول معاناة الفرد و التعامل بو عي ولطف مع الذات و عدم الحكم عليها. 


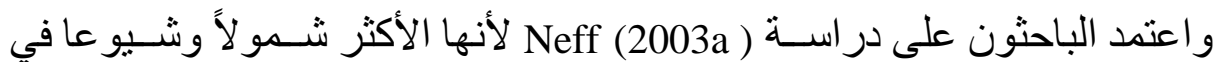

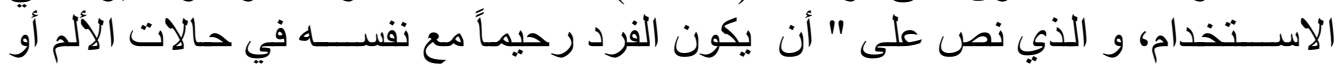

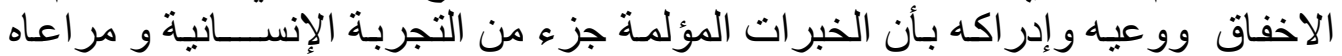

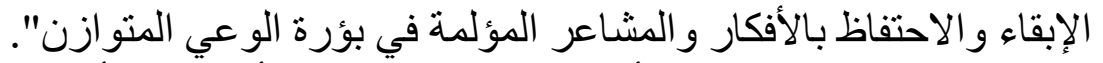

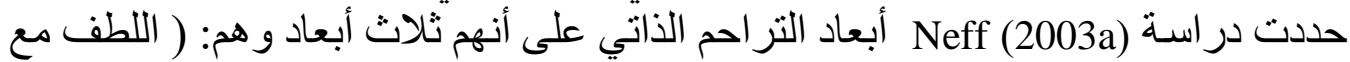

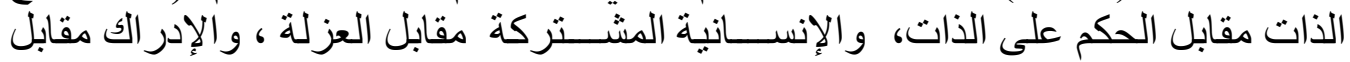

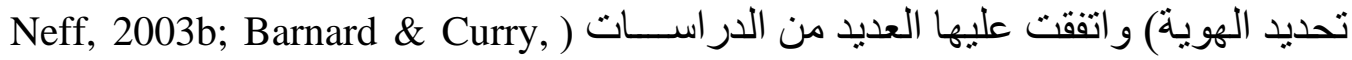
2011; Raes et al., 2011; Sun \& Chan, 2016; Proeve \& Kenny, 2018; Bloch, 2017; (López et al., 2018; Wu et al., 2019; Weinstock et al., 2020 لهذه الأبعاد على النحو الآتي: (Neff, 2003a):

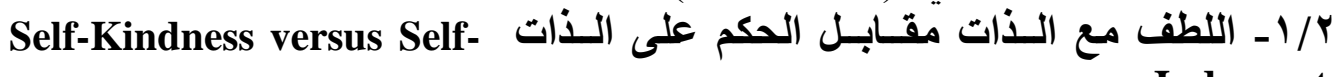

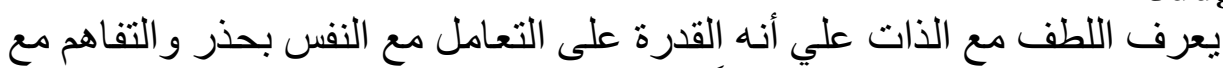

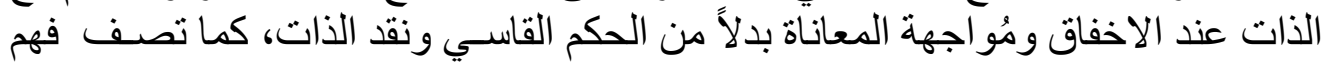

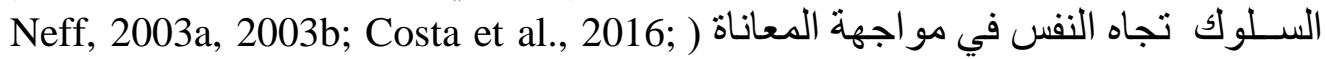
(Weinstock et al., 2020 على النقيض يشَبر الحكم على الذات Self-Judgment إلى النقد القاسـي لأخطائه

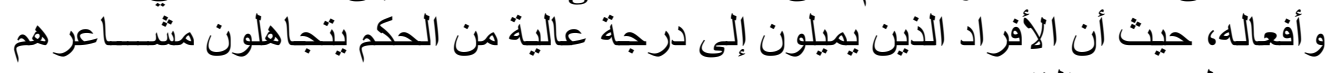

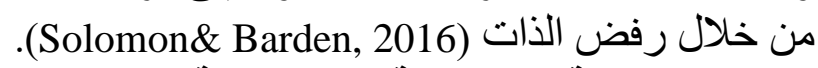

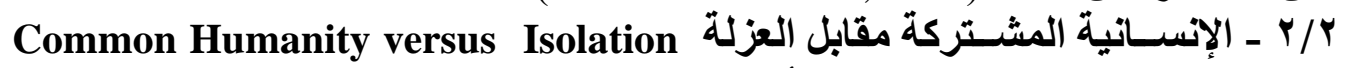

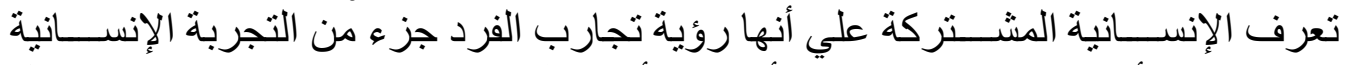

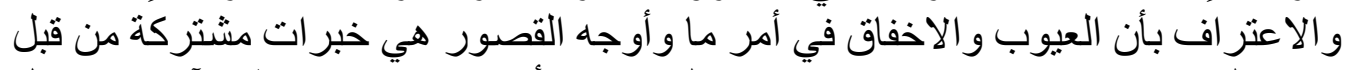

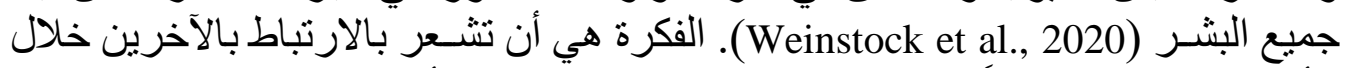

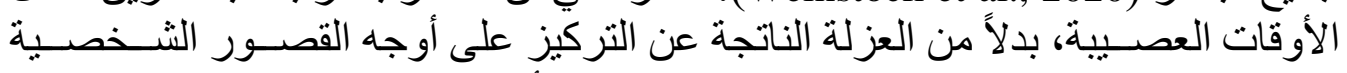

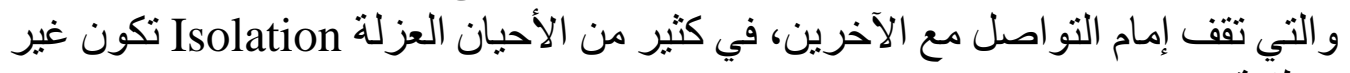
منطقية (Neff , 2011).

كما أن العزلة في بعض الأحيان تجعل الأفراد في ألم أو شـعور بالإحباط وتقطع علاقاتهم

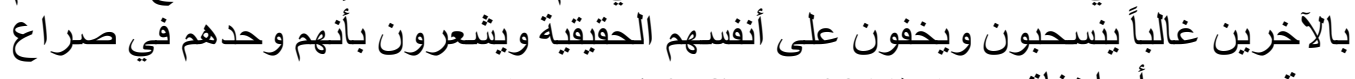

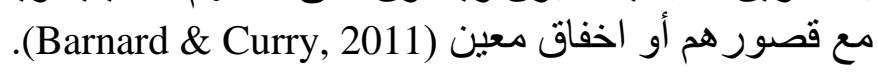

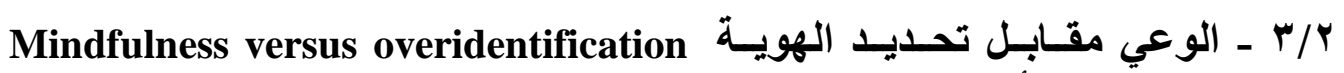

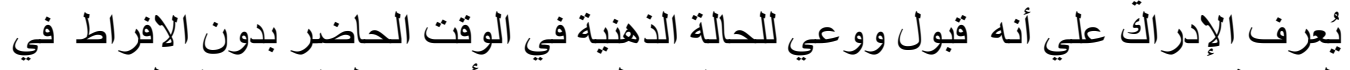

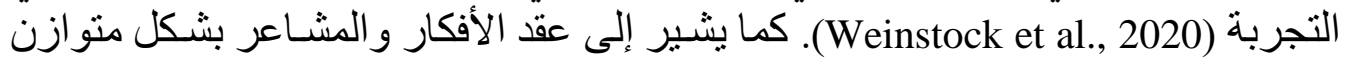




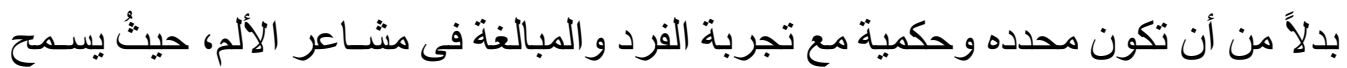

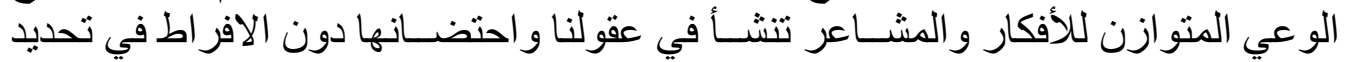

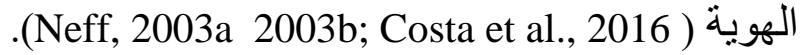

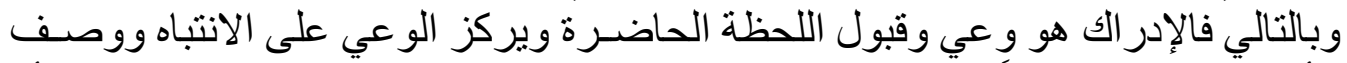

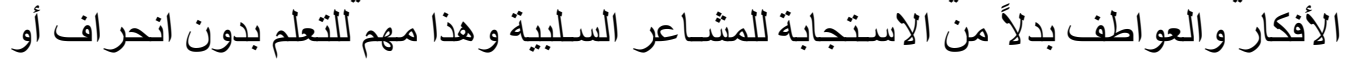

قلق بشأن المستقبل (Kabat-Zinn, 2003).

وعرفت دراســة (Gilbert \& Procter, 2006; Neff \& Vonk, 2009) تحديد الهوية overidentification

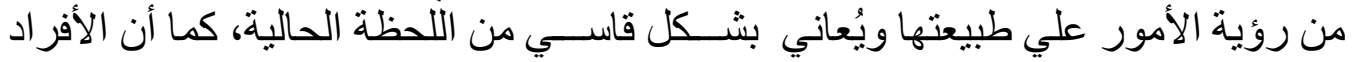

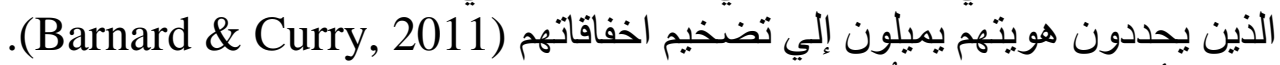

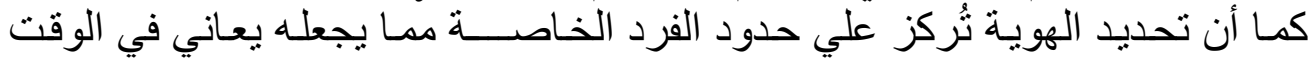

الحاضر (Gilbert \& Procter, 2006; Neff \& Vonk, 2009).

وبالتالي فالو عي يقاوم التحديد و التجنب ويعتبر حلاً وسطاً بينهما، حيث أن الأفر اد

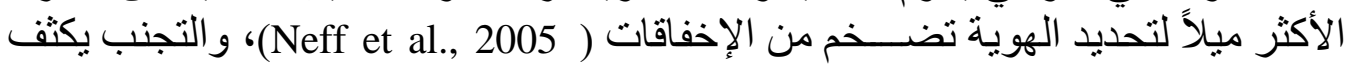

المشاعر السلبية علي المدى الطويل (Germer, 2013; Bernard and Curry, 2011 ).

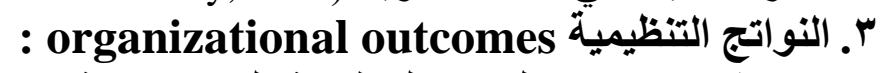

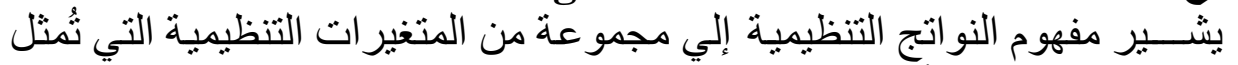

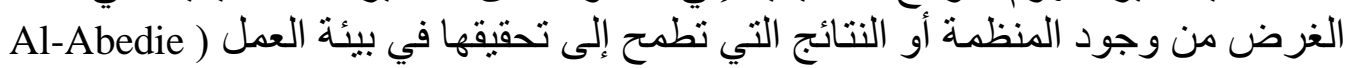
. \& Al-Temini, 2015

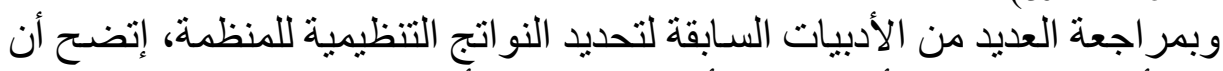

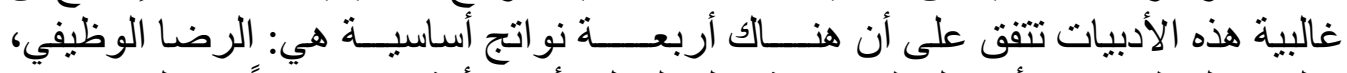

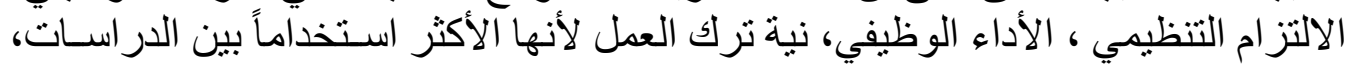

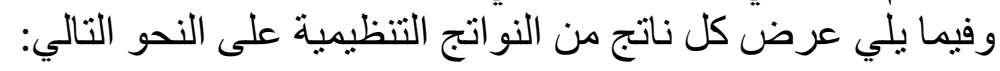

(Kath et al., 2010; Simha and Cullen, 2012; Diedericks and Rothmann, 2014; Hendrix et al., 2015; Hwang and Hopkins, 2015; Samad , 2015 )

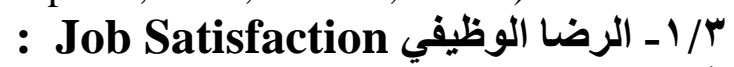

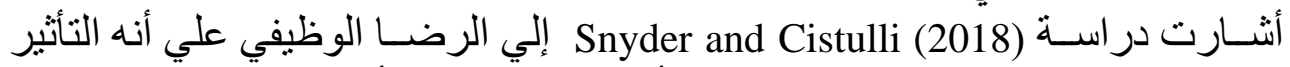

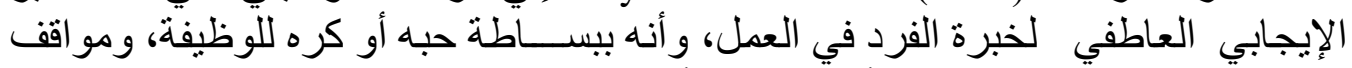

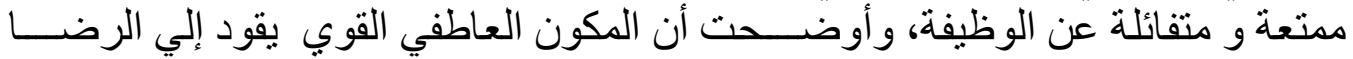
وبينت دراسة Narzary and Palo (2020) الرضـا الوظيفي بأنه حالة عاطفية ممتعة

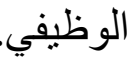
ناتجة من تقييم الأداء الوظيفي. 


\section{: Organizational commitment}

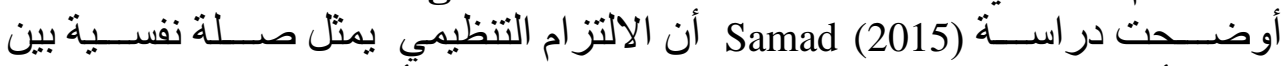

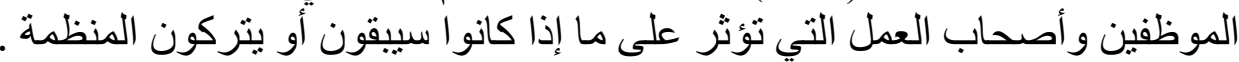

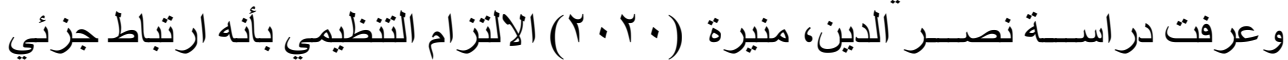

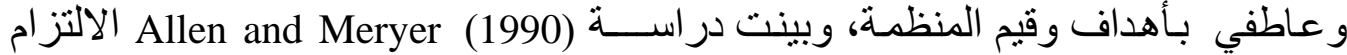

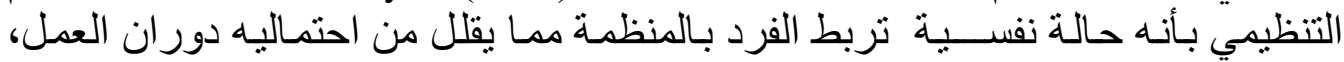

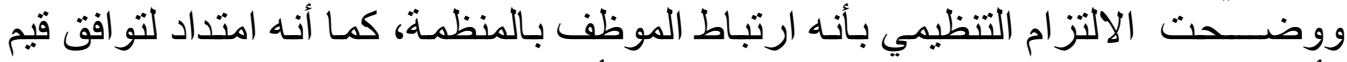
و أهداف المنظمة مع توجهات ألموظف للتحقيق الأهداف التهاف التنظيمية.

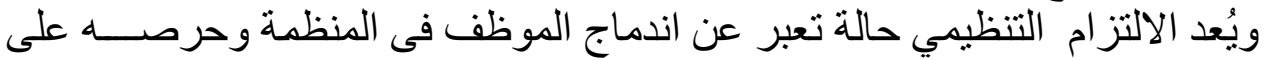

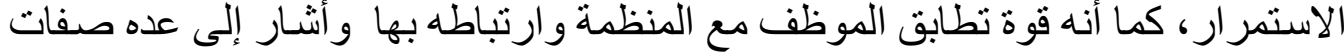

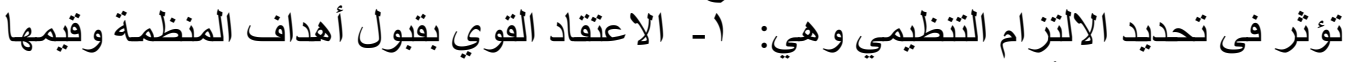

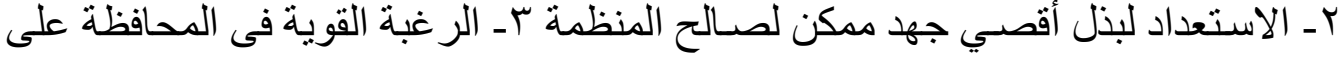

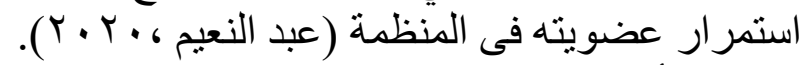

r/r آس الأداء الوظيفي Job Performance

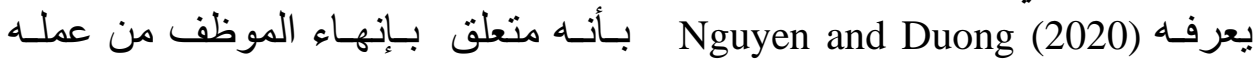
وو اجباته التي يتم إعطاءها من قبل الإدارة العليا في المنظمة.

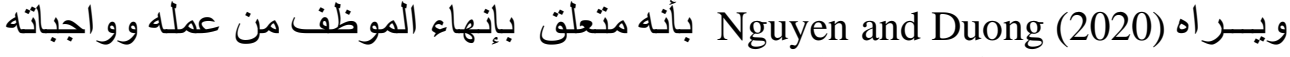

التي يتم إعطاءها من قبل الإدارة العليا في المنظمة.

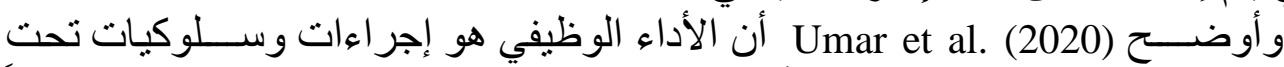

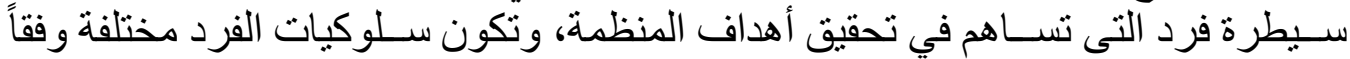

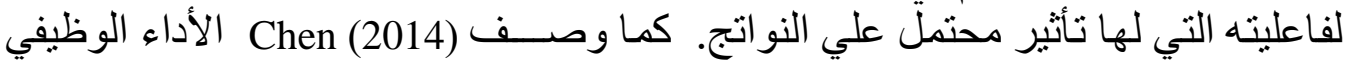

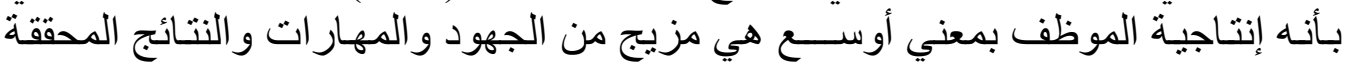

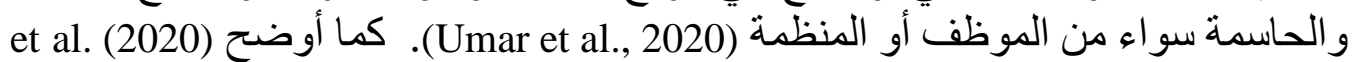

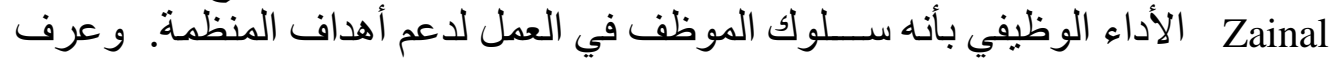

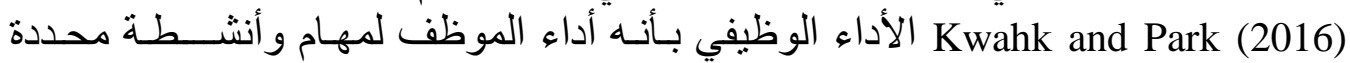

(Sriviboon, 2020)

: Turnover Intention

عرفت دراسـة (2014) Diedericks and Rothmann أن انخفاض الالتز ام التنظيمي

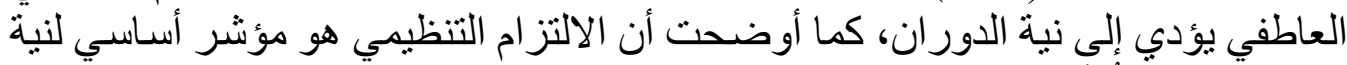

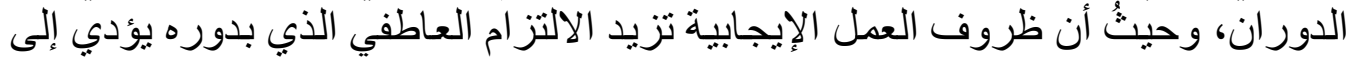
انخفاض دور ان الموظف. 
كما أظهرت در اسة Snyder and Cistulli (2018) أن نية الدوران أحد أشكال الخروج

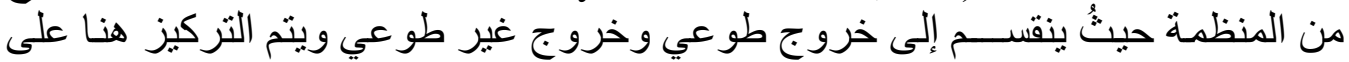

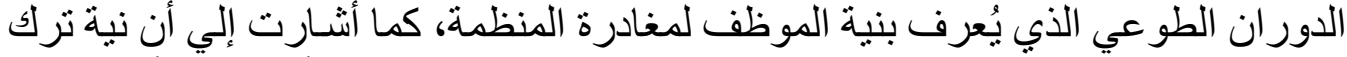

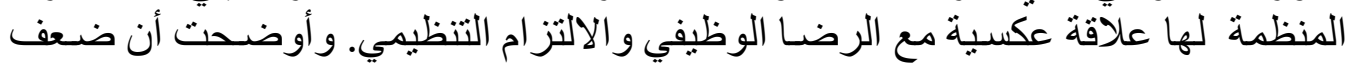

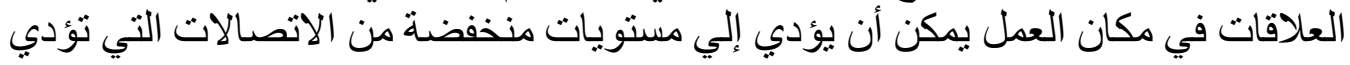

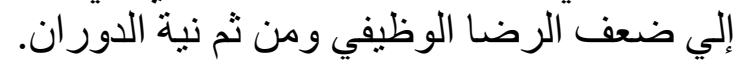

\section{ب/ ع ـ العلاقة بين التوجيه المهني والتراحم الذاتي: التي:}

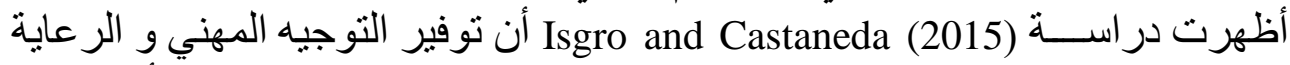

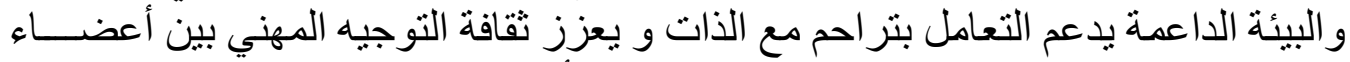

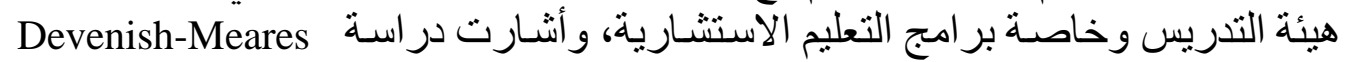

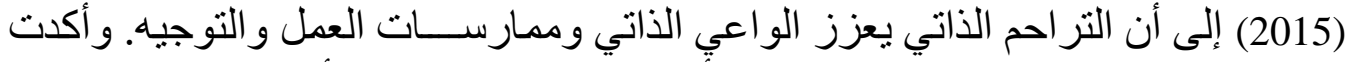

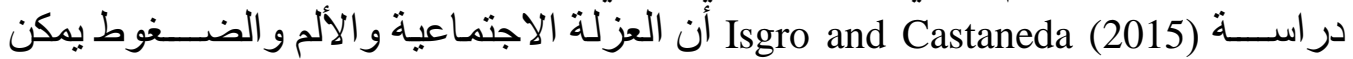

$$
\text { تخفيفها من خلال التوجيه المهني الفردي. }
$$

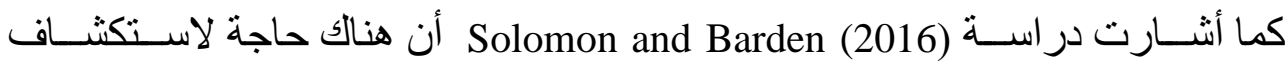

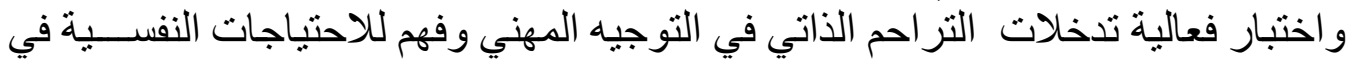

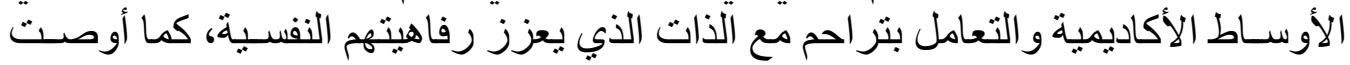

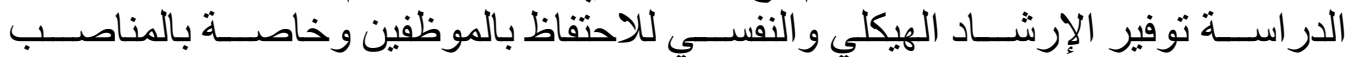

ووجدت در اســة Amemiya and Sakairi (2020) الدعم الاجتماعي يرتبط بالتر احم

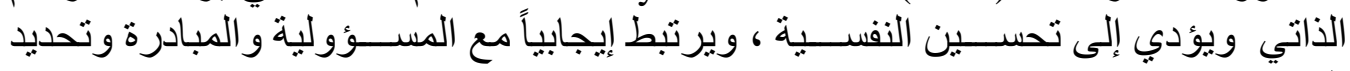

كما أوضحت در اسة (2020) kao et al., أن التوجيه مهم لاستثمار الموارد المهنية

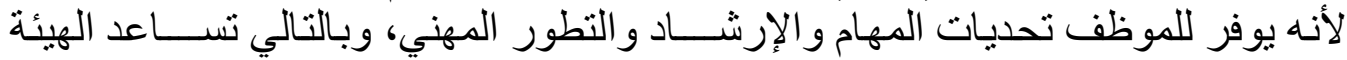

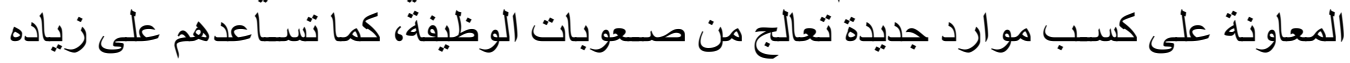

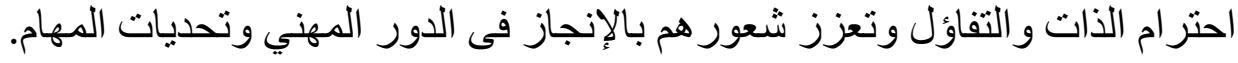

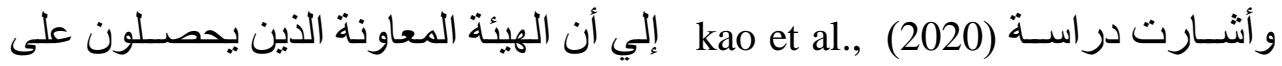

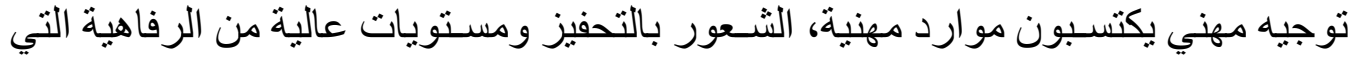

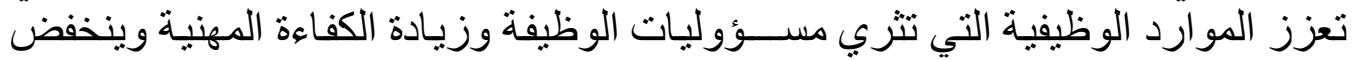
لديهم الركود المهني الذي يؤدي إلى الاسـتنفاد العاطفي. وبناء على ما ســق من در اسـات 
يتوقع الباحثون وجود علاقة بين التوجيه المهني و التزر احم الذاتي، حيث يمكن صــيـاغة

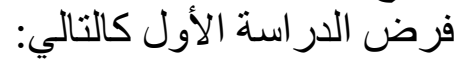

\section{H1 يوجد تأثير معنوي للتوجيه المهني على التراحم الذاتي. ؛. العلاقة بين التوجيه المهني والنواتج التنظيمية:}

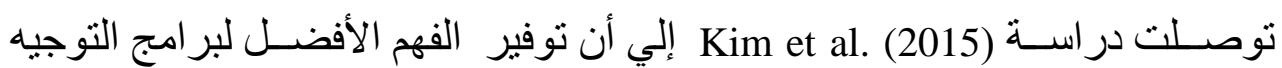

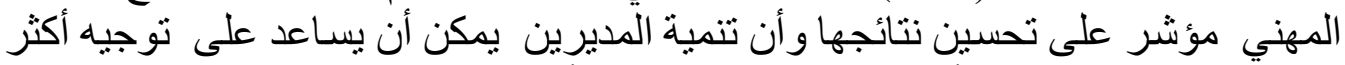

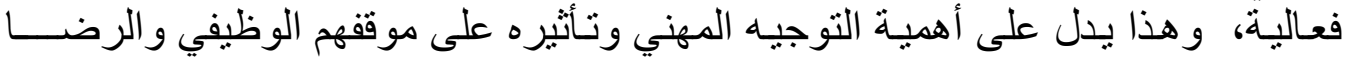

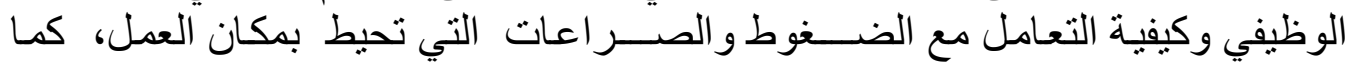

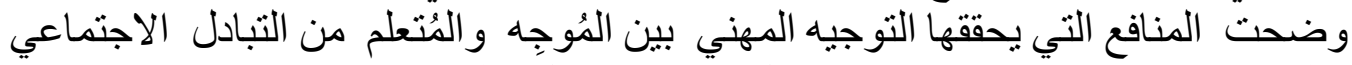
و التنمية المجتمعية التي تتحقق من خلال التعلم المنبادل والنمو الثخصي.

وتقتر ح دراسـة (2015 ) أنه يجب على ألى المؤسسات الأكاديمية

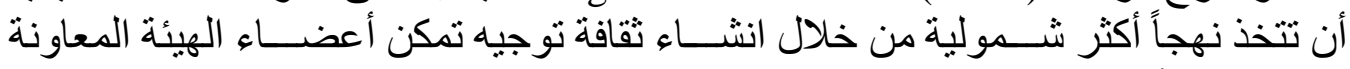

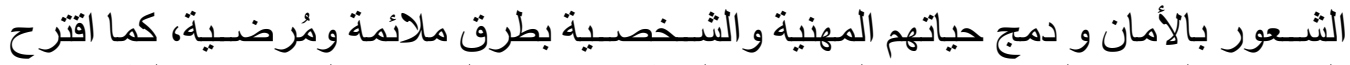

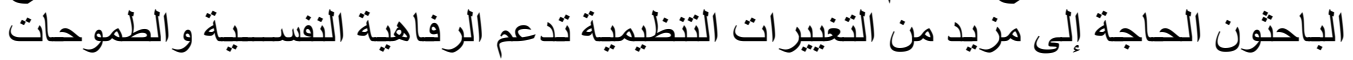
المهنية في مجال العمل الأكاديمي.

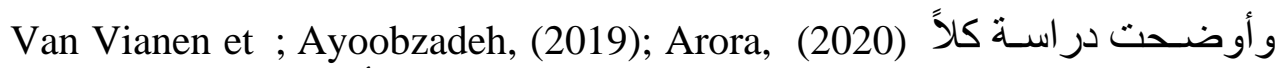

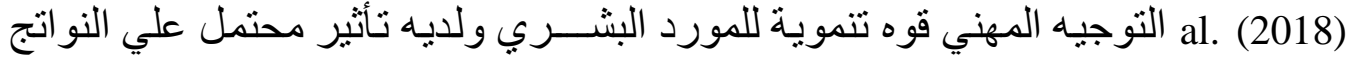
التنظيمية للموظفين مثل الرضا الوظيفي الوني والنجاح المهني و الترقيات.

وبينت دراســة Kumar\& Budhwar (2020) أن هناك العديد من الأدو ات الإيجابية

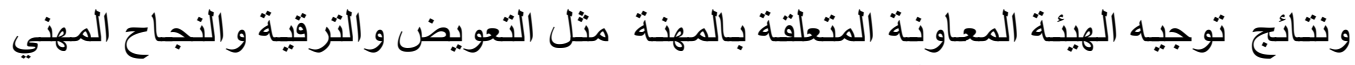
المدرك و العلاقات الذاتية مثل رفاهية الموظف .

و أثــــارت العديد من الدراســات إلي أن توفير المعرفة المهنية و التدريب و الحماية

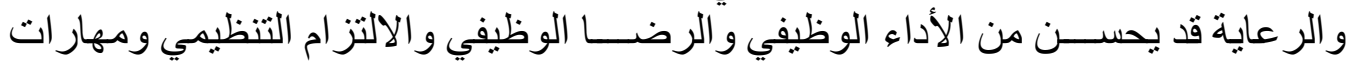

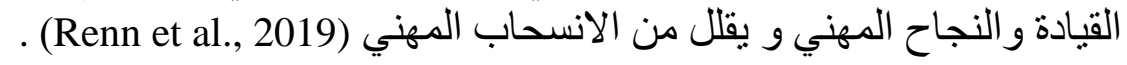

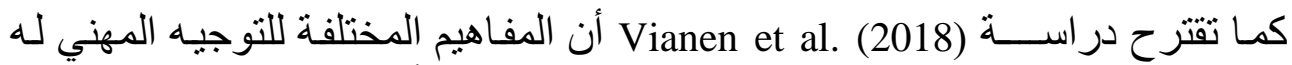

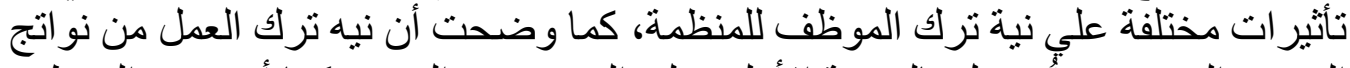

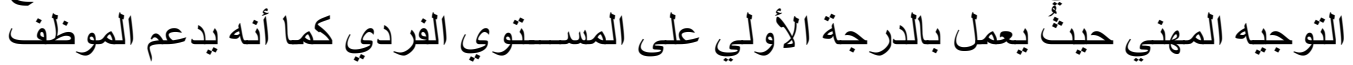

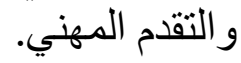


كما أن الموجه يدفع إلي الرضـا الثـخصـي من خلال تعلم الموظف معرفة جديدة

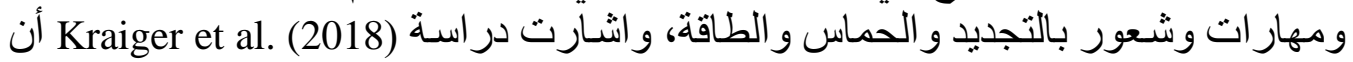

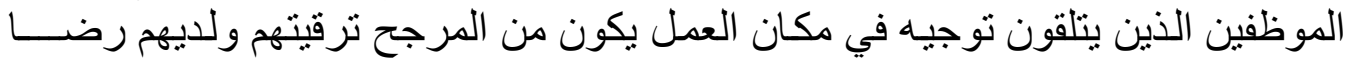

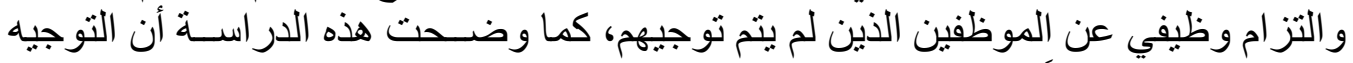

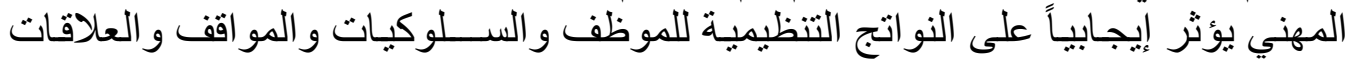

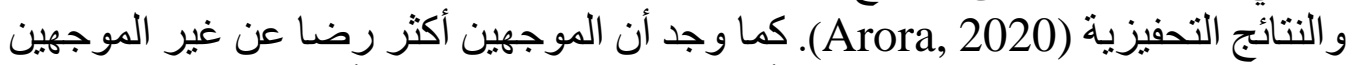

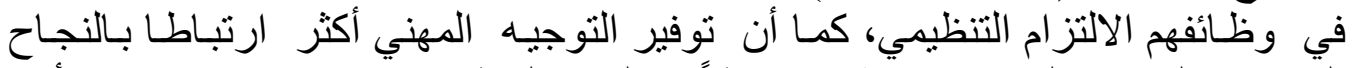

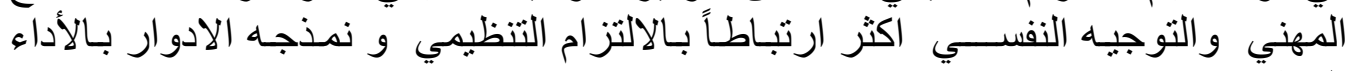
التنظيمي(siengthai et al.,2020).

كما أن التوجيه الفعال يُمكن من التعلم و تعزيز المهار ات، ووضحت هذئ هذه الدراسة

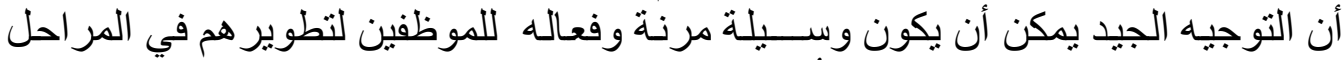

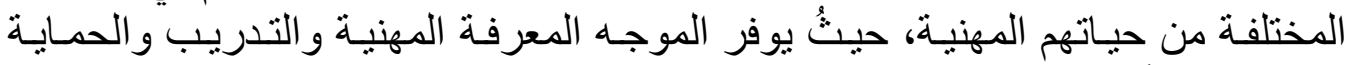

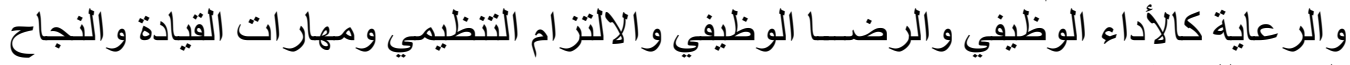
المهني للموظف (Arora, 2020).

و وأنشارت در اسة (2020) kao et al., أن التوجيه المهني فرصة للتنمية المهنية

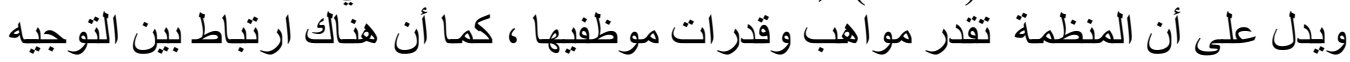

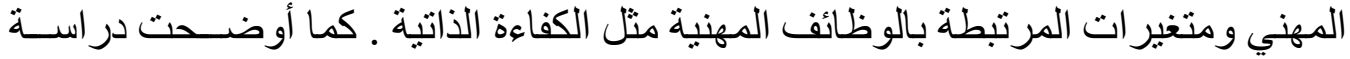

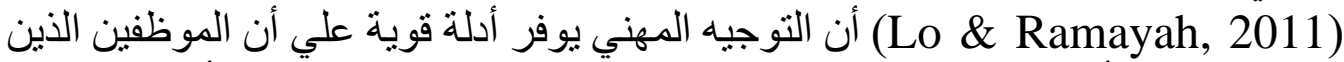

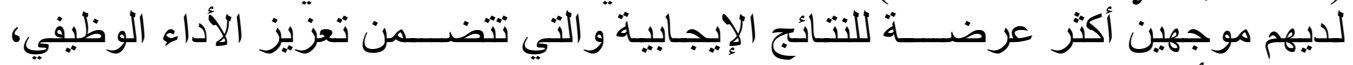

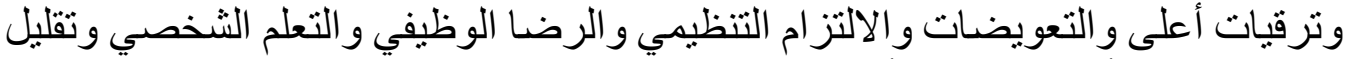

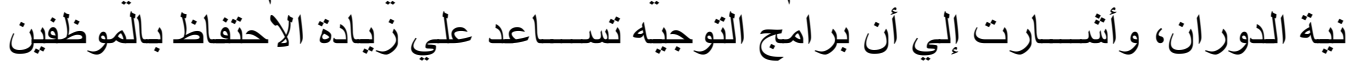
والرضا المهني، تنسريع تطوير القيادة (Siengthai et al., 2020).

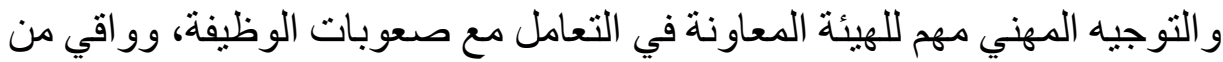

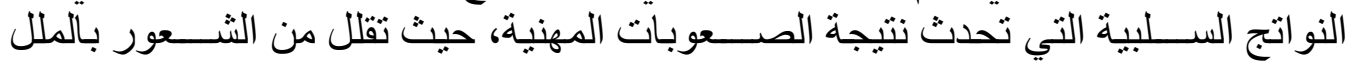

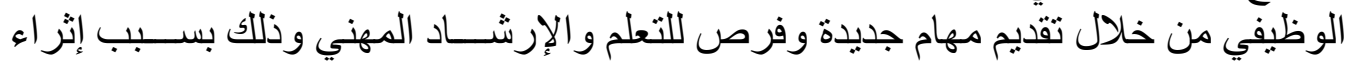

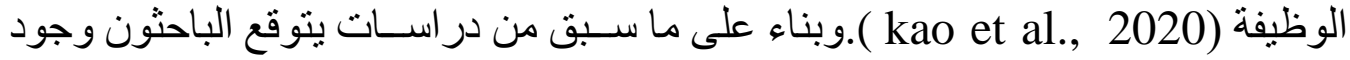

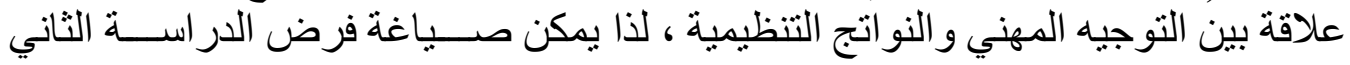




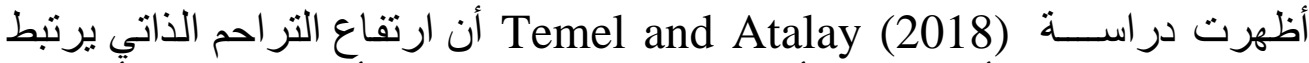

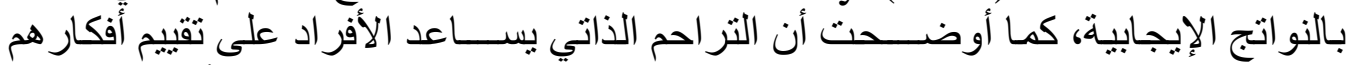

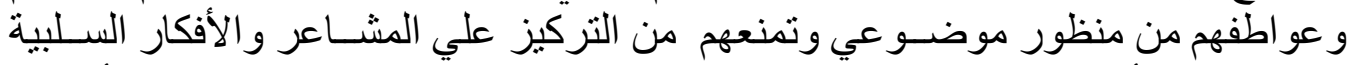

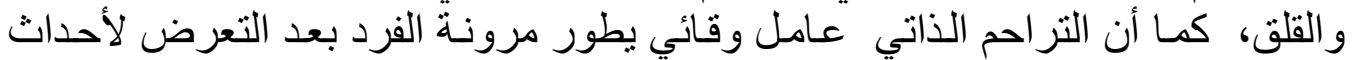
الحياة السلبية وبالتالي ينُظر للتر احم الذاتي باعتباره عامل يرتبط بتحسين التكييف النفسي لأنسي للفرد.

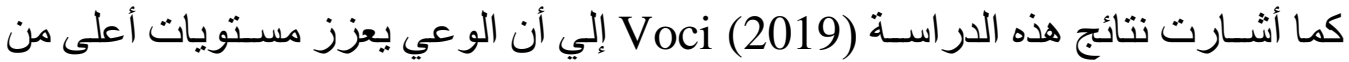

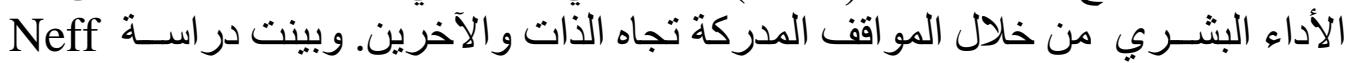
and Beretvas (2013) أن التراحم الـذاتي يحســـن من العـلاقــات في مكــان (Iacono,2017) ( العمل (2013) (

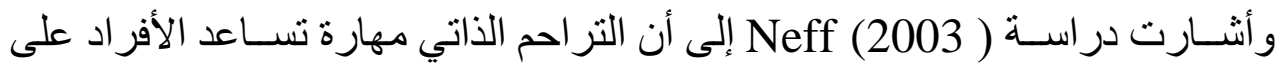

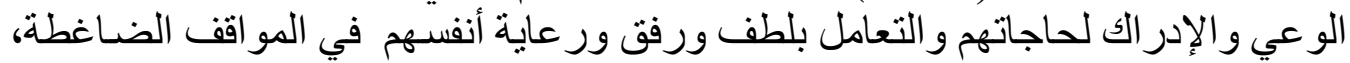

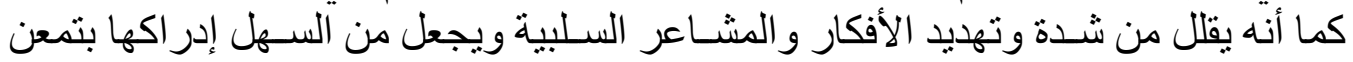

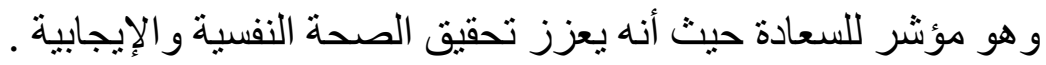

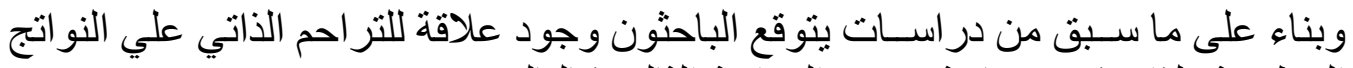
التنظيمية، لذا يمكن صياغة فرض الدر اسة الثالث كالتالي: H3: يوجد تأثير معنوي التراحم الأتي علي النواتج التنظيمية. 7. توسيط التراحم الذاتي في العلاقة بين التوجيه المهني والنواتج التنظيمية:

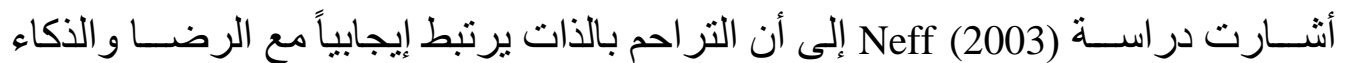

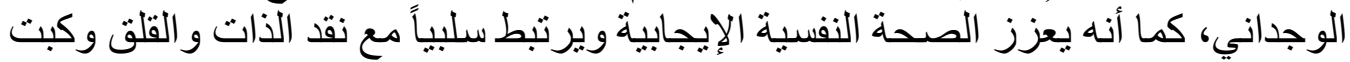

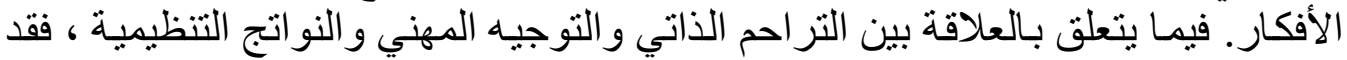

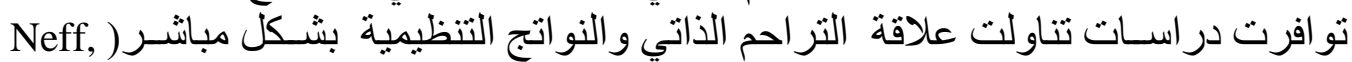
2011; Zessin et al., 2015; Felder, 2016 ; Voci, 2019;

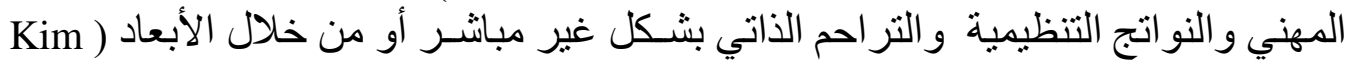
et al., 2015; Ghosh \& Reio, 2013; Chen \& Hu, 2017; Griffiths et al., 2018; Isgro \& Castaneda, 2015; Solomon\& Barden, 2016; Barnard \& Curry, 2011; Macbeth من Gumley, 2012 \& و و لا يوجد دراسـة تناولت تأثير التوجيه المهني على النواتج التنظيمية من خلال توسيط التراحم الذاتي. 


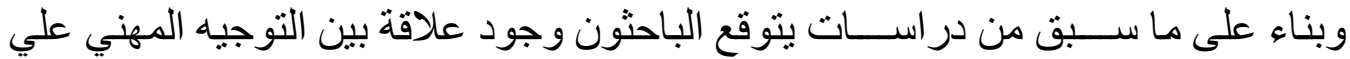

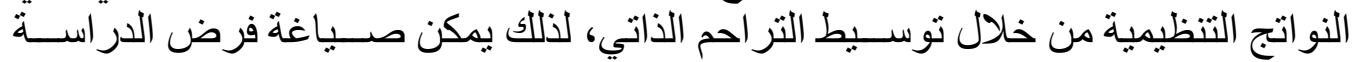

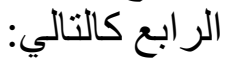

التراحم الذاتي. تأثير معنوي للتوجيـه المهني علي النواتج التظيمية من خلال توســيط

وبناءً على ما سبق من علاقات بين متغيرات الدراسة، فإن الإطار المفاهيمي لهذه

المتغير ات يمكن توضيحه في الشكل (1)

$\mathrm{H} 2$

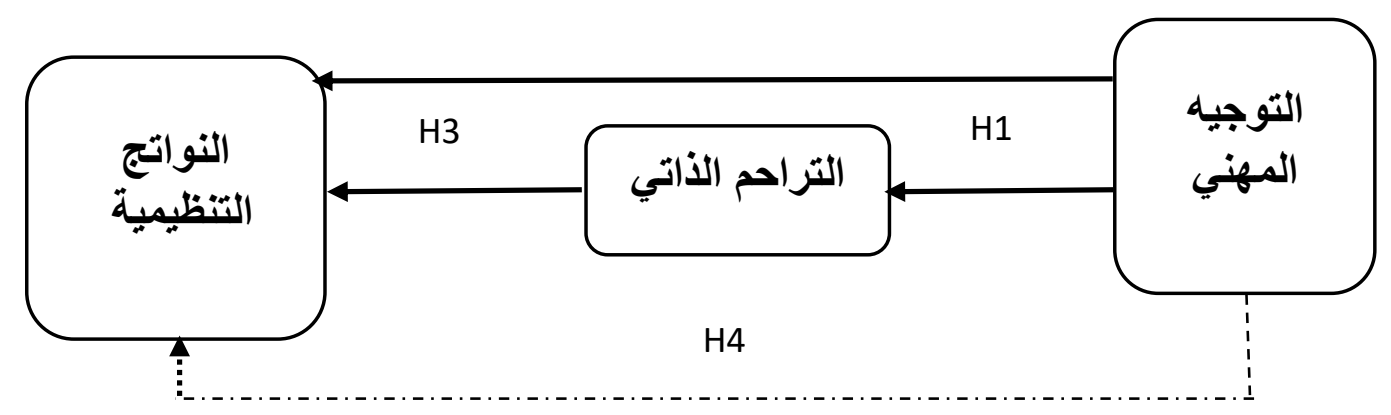

المصدر: إعداد الباحثون.

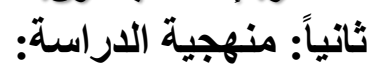

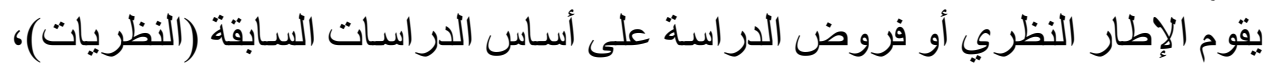

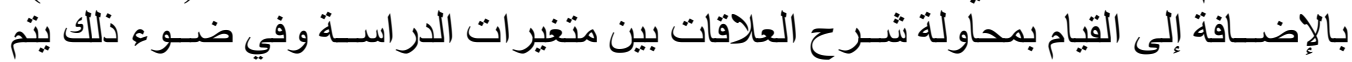

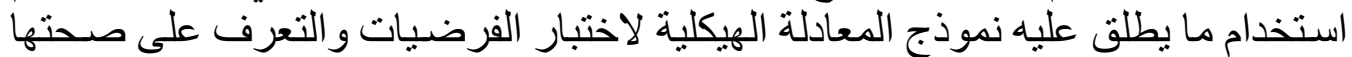

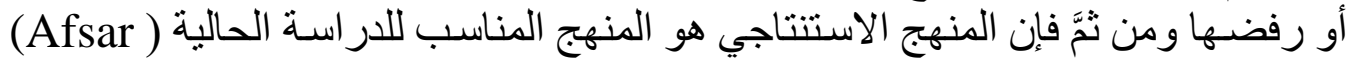

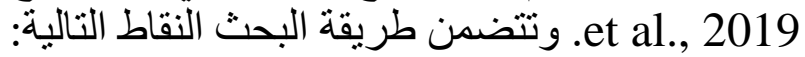

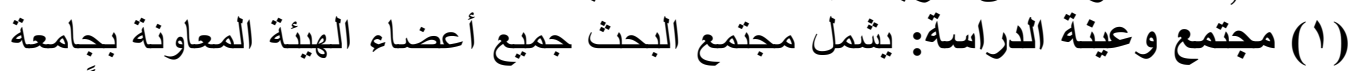

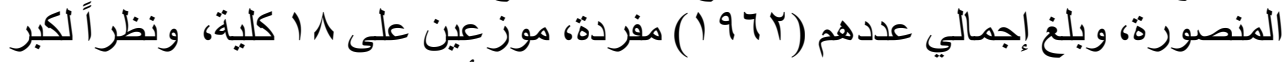

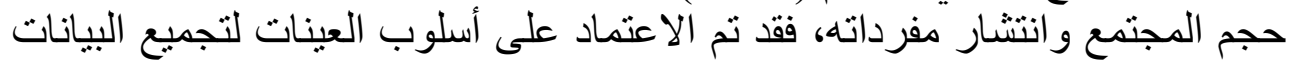

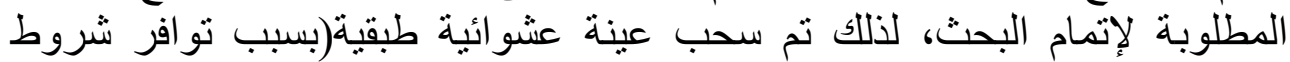

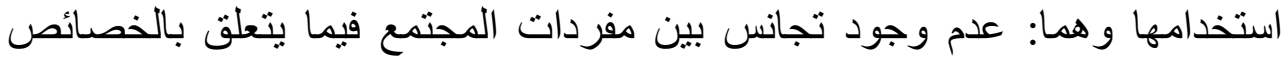

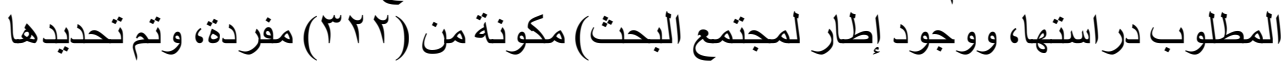

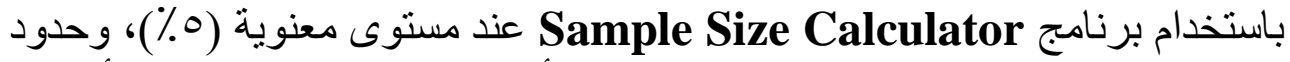
ثقة (90\%)، وتم توزيع هذه العينة بالاعتماد على أسلوب التوزيع النسبي الذي يأخذ في 
اعتباره التباين بين عدد المفردات داخل كل طبقة (كل طبقة تمثل كلية من كليات

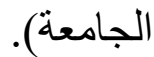

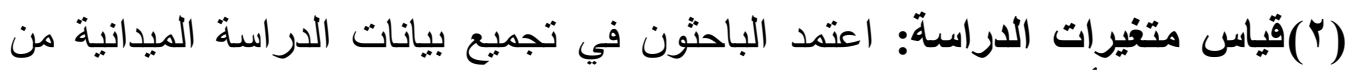

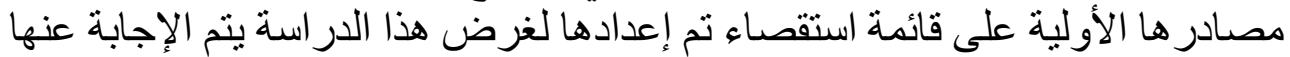

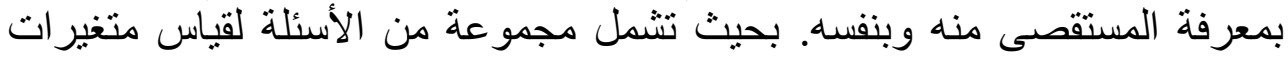

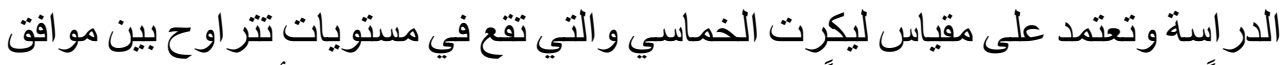

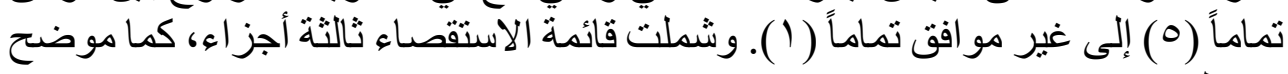

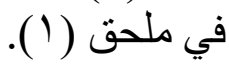

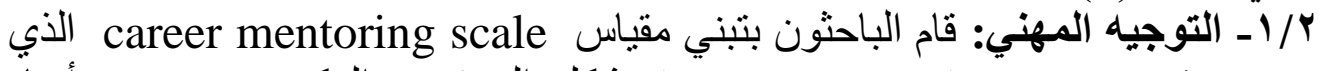

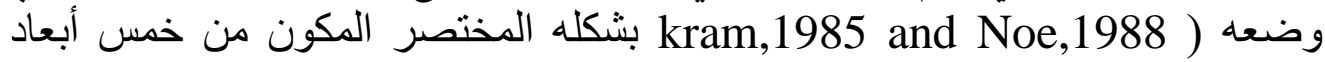

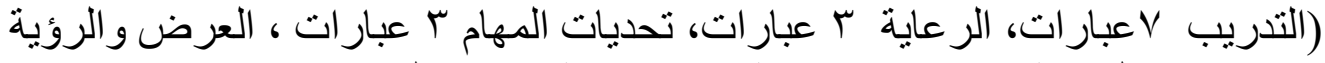

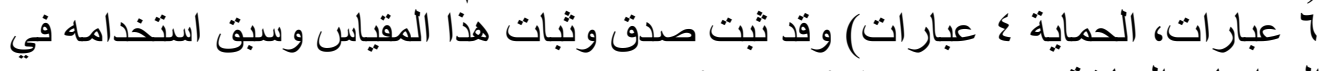
الدر اسات السابقة (Coppin \& Fisher, 2020).

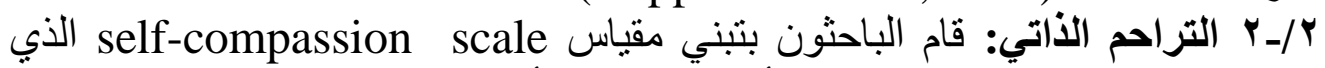

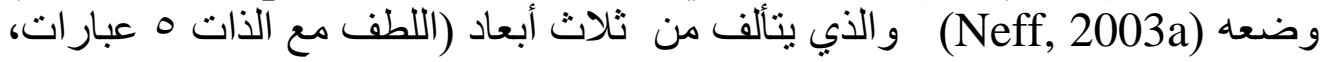

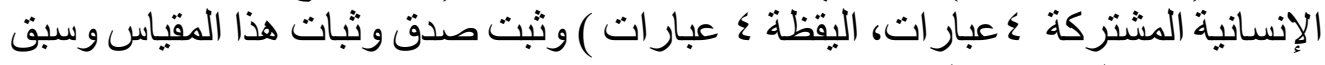

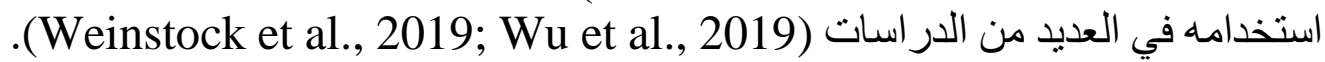

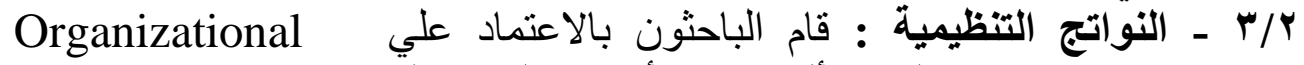

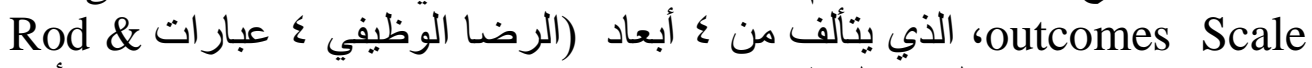
Rod \& Ashill, 2010 ، Ashill, 2010

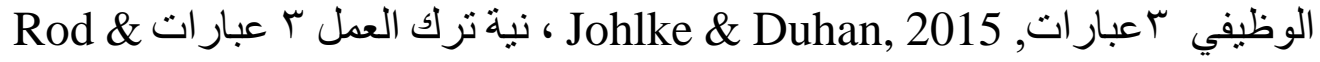
(Ashill, 2010,

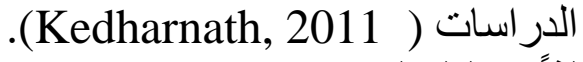

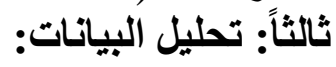

اعتمد الباحثون على أسلوب تحليل المسار لاختبار الفروض باستخدام برنامج

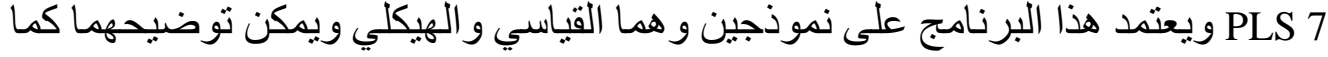

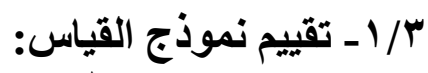

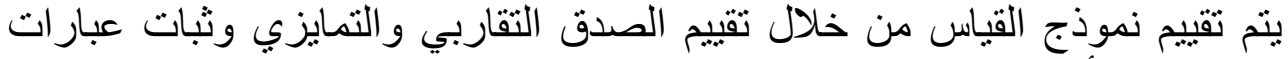

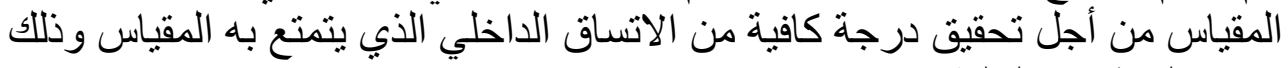
باتباع الخطو ات التالية: 
I/ / 1/ ـ قياس صدق عبارات المقياس: Individual Item Validity

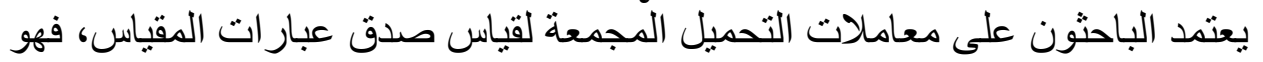

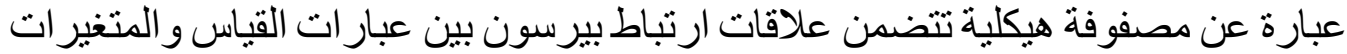

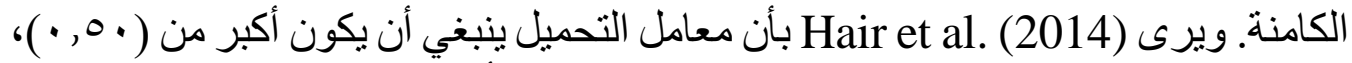

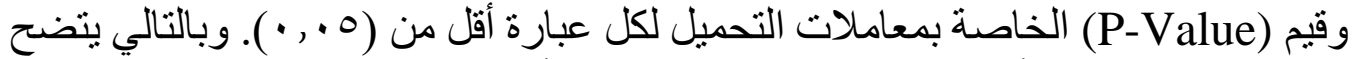

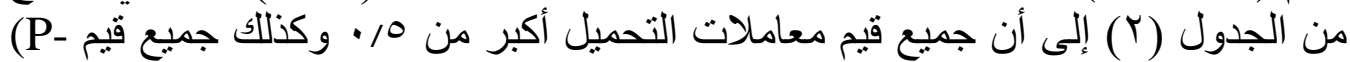

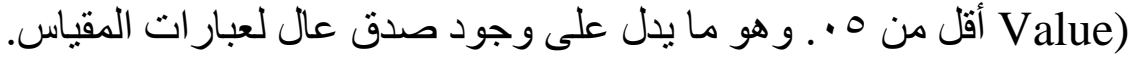

كروناخ r/T- حساب معامل الثبات المركب (Composite Reliability) ومعامل ألفا

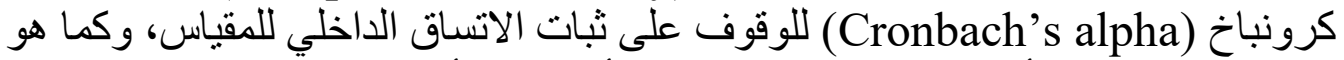

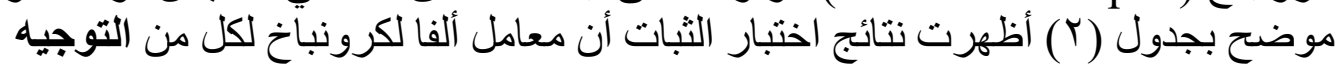

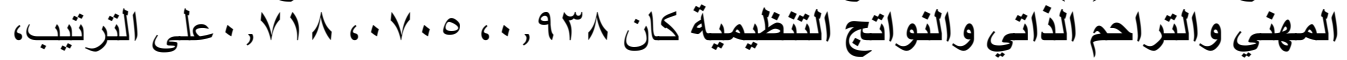

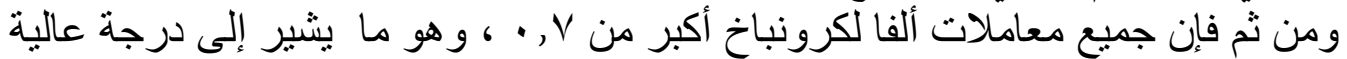

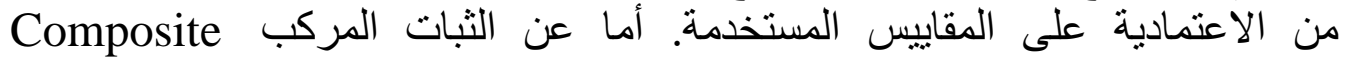
Reliability (CR)

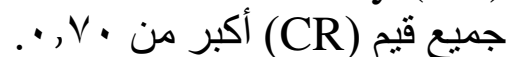

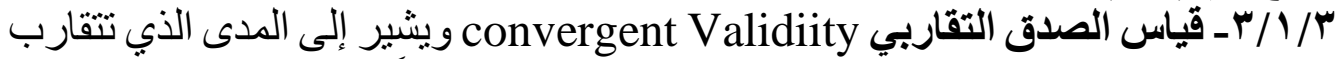

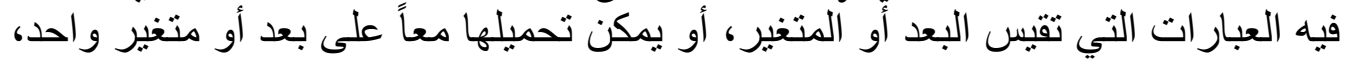

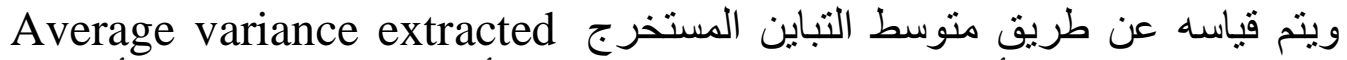

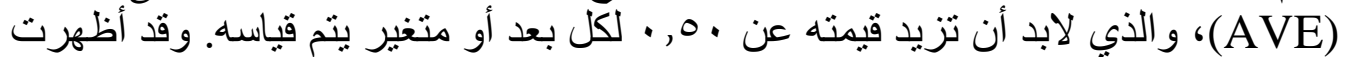

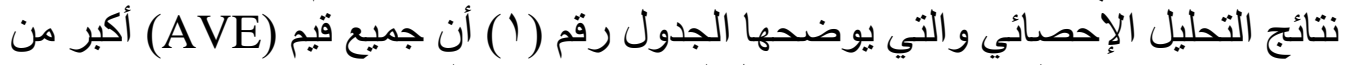
0, • و هو ما يشير إلى صدق تقاربي عال لجميع متغير ات الدر اسة.

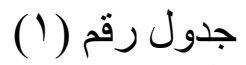

معاملات التحميل و الثبات و الصدق التقاربي

\begin{tabular}{|c|c|c|c|c|c|c|}
\hline $\begin{array}{l}\text { التقاربى } \\
\text { (AVE) } \\
\text { (AVE) }\end{array}$ & المركبات & 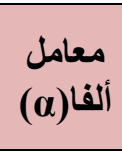 & التحميل & العبارات & البعد & المتغير \\
\hline \multirow{5}{*}{0.803} & \multirow{5}{*}{0.953} & \multirow{5}{*}{0.938} & $(0.779)$ & CO1 & \multirow{5}{*}{ التدريب } & \multirow{5}{*}{ التوجيهالمهني } \\
\hline & & & $(0.677)$ & $\mathrm{CO2}$ & & \\
\hline & & & $(0.744)$ & $\mathrm{CO3}$ & & \\
\hline & & & $(0.727)$ & CO4 & & \\
\hline & & & $(0.766)$ & $\mathrm{CO5}$ & & \\
\hline
\end{tabular}




\begin{tabular}{|c|c|c|c|c|c|c|}
\hline $\begin{array}{l}\text { التقاربى (AVE) } \\
\text { (AVE) }\end{array}$ & $\begin{array}{l}\text { المركب } \\
\text { الثبات } \\
\text { الثR }\end{array}$ & ألفامعامل & التحميل & العبارات & البعد & المتغير \\
\hline & & & $(0.705)$ & CO6 & & \\
\hline & & & $(0.725)$ & CO7 & & \\
\hline & & & $(0.875)$ & SP1 & & \\
\hline & & & $(0.895)$ & SP2 & الرعاية & \\
\hline & & & $(0.761)$ & SP3 & & \\
\hline & & & $(0.862)$ & CA1 & & \\
\hline & & & $(0.807)$ & CA2 & المديات & \\
\hline & & & $(0.893)$ & CA3 & & \\
\hline & & & $(0.824)$ & EX1 & & \\
\hline & & & $(0.836)$ & EX2 & & \\
\hline & & & $(0.846)$ & EX3 & العرض & \\
\hline & & & $(0.739)$ & EX4 & والروئة & \\
\hline & & & $(0.770)$ & EX5 & & \\
\hline & & & $(0.805)$ & EX6 & & \\
\hline & & & $(0.841)$ & PR1 & & \\
\hline & & & $(0.847)$ & PR2 & الحماية & \\
\hline & & & $(0.875)$ & PR3 & الحمايه & \\
\hline & & & $(0.850)$ & PR4 & & \\
\hline \multirow{11}{*}{0.635} & \multirow{11}{*}{0.837} & \multirow{11}{*}{0.705} & $(0.705)$ & SK1 & \multirow{5}{*}{ اللطف مع } & \multirow{11}{*}{ التراحم الذاتي } \\
\hline & & & $(0.836)$ & SK2 & & \\
\hline & & & $(0.864)$ & SK3 & & \\
\hline & & & $(0.615)$ & SK4 & & \\
\hline & & & $(0.808)$ & SK5 & & \\
\hline & & & $(0.745)$ & CH1 & \multirow{4}{*}{ الإلنتركةنة } & \\
\hline & & & $(0.848)$ & CH2 & & \\
\hline & & & $(0.813)$ & CH3 & & \\
\hline & & & $(0.808)$ & CH4 & & \\
\hline & & & $(0.845)$ & MF1 & \multirow{2}{*}{ اليقظة } & \\
\hline & & & $(0.851)$ & MF2 & & \\
\hline
\end{tabular}




\begin{tabular}{|c|c|c|c|c|c|c|}
\hline $\begin{array}{l}\text { التقاربى } \\
\text { (AVE) }\end{array}$ & $\begin{array}{l}\text { المركبات } \\
\text { الثم) }\end{array}$ & 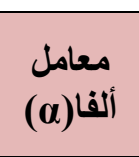 & معاملات & العبارات & البعد & المتغير \\
\hline & & & $(0.726)$ & MF3 & & \\
\hline & & & $(0.754)$ & MF4 & & \\
\hline \multirow{17}{*}{0.519} & \multirow{17}{*}{0.792} & \multirow{17}{*}{0.718} & $(0.646)$ & OC1 & \multirow{7}{*}{ التنظيمي } & \multirow{17}{*}{ التنظيمية } \\
\hline & & & $(0.825)$ & OC2 & & \\
\hline & & & $(0.828)$ & $\mathrm{OC3}$ & & \\
\hline & & & $(0.785)$ & OC4 & & \\
\hline & & & $(0.898)$ & OC5 & & \\
\hline & & & $(0.719)$ & OC6 & & \\
\hline & & & $(0.853)$ & OC7 & & \\
\hline & & & $(0.629)$ & JS1 & \multirow{4}{*}{ الوظيفي } & \\
\hline & & & $(0.904)$ & JS2 & & \\
\hline & & & $(0.877)$ & JS3 & & \\
\hline & & & $(0.820)$ & JS4 & & \\
\hline & & & $(0.892)$ & JP1 & \multirow{3}{*}{ الوظيفي } & \\
\hline & & & $(0.839)$ & JP2 & & \\
\hline & & & $(0.941)$ & JP3 & & \\
\hline & & & $(0.591)$ & TI1 & \multirow{3}{*}{ نية ترك } & \\
\hline & & & $(0.938)$ & TI2 & & \\
\hline & & & $(0.926)$ & TI3 & & \\
\hline
\end{tabular}

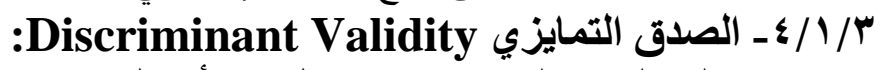

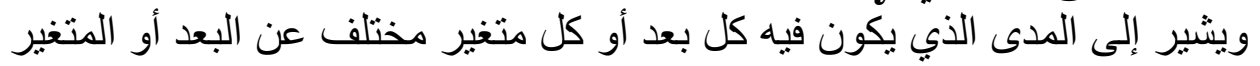

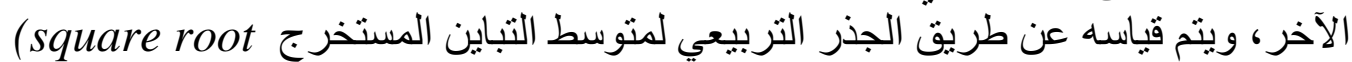

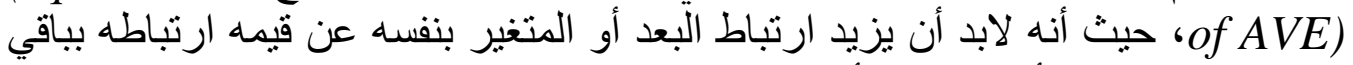

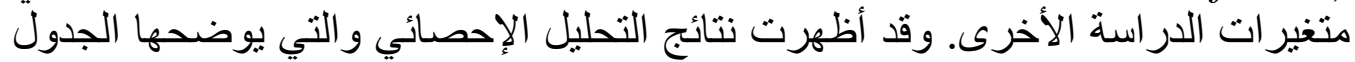
رقم (Y) أن جميع القيم مقبولة. 


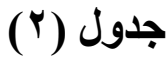

مصفوفة الارتباط بين المتغير ات والجذر التربيعي دل (AVE).

\begin{tabular}{|c|c|c|c|}
\hline النواتج التنظيمية & التراحم الذاتي & التوجيه المهني & المتغير \\
\hline & & $(0.896)$ & التوجيه المهني \\
\hline & $(0.797)$ & 0.302 & التراحم الذاتي \\
\hline$(0.721)$ & 0.331 & 0.606 & النواتج التنظيمية \\
\hline
\end{tabular}

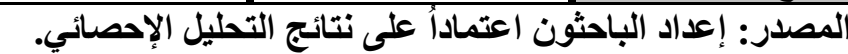

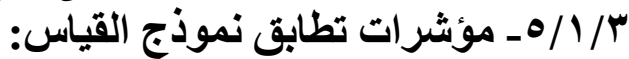

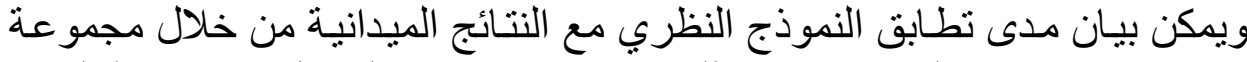

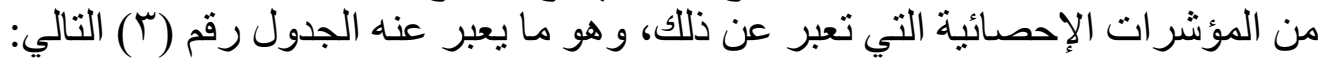

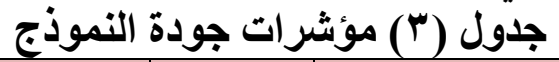

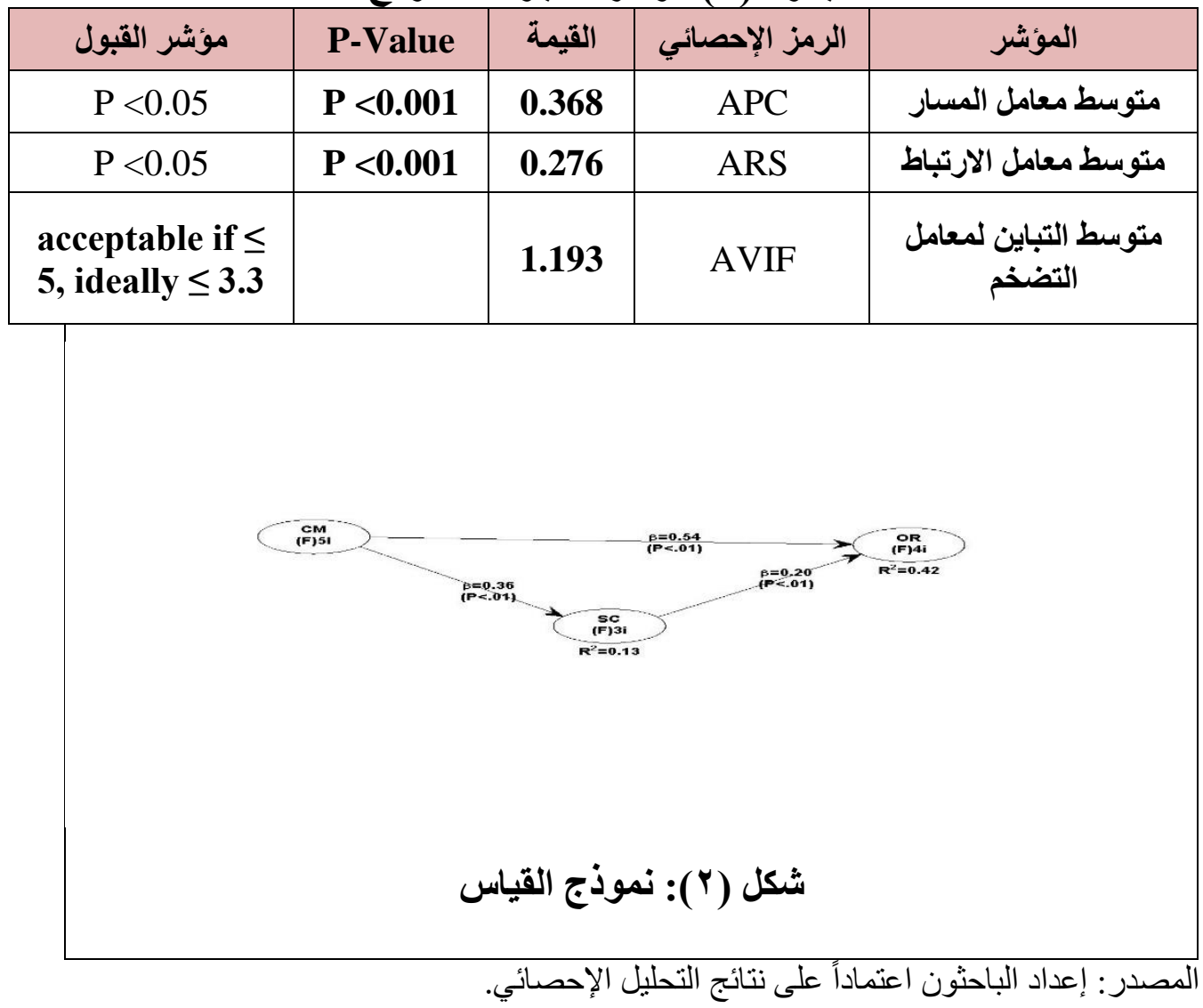

r/ץ - النموذج الهيكلي للاراسة: Structural Equation Modeling (Sem) 


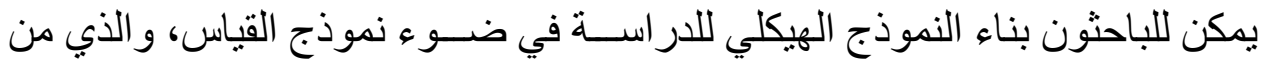

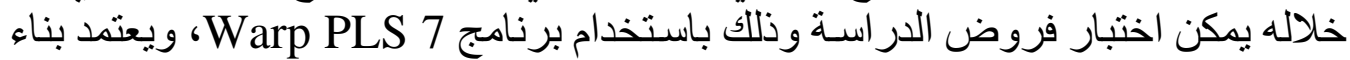

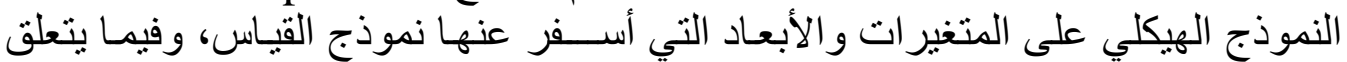

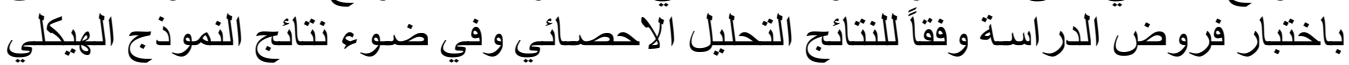

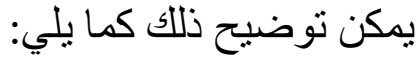

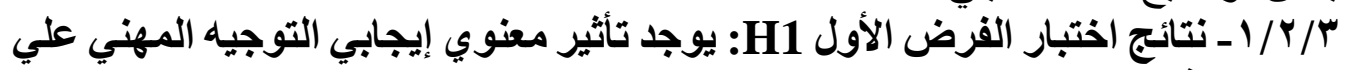

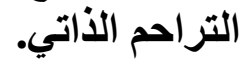

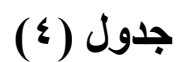

نتائج تحليل المسار للتأثيرات المباشرة التوجيه المهني علي التراحم الذاتي.

\begin{tabular}{|c|c|c|c|c|}
\hline $\begin{array}{c}\text { المعنوية } \\
\text { P-Value }\end{array}$ & قيمة معامل & التابعير & المتغير المستقل & الفرض \\
\hline$<0.001$ & 0.363 & الذاتراحم & التوجيه المهني & H1 \\
\hline
\end{tabular}

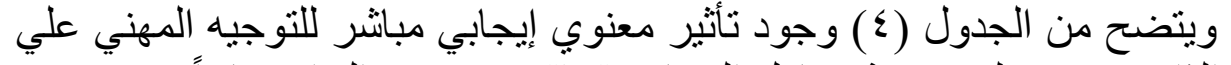

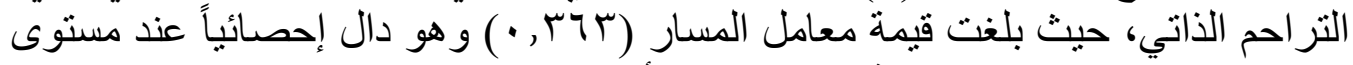

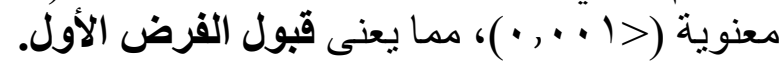

ب/r/r/r آنتائج اختبار الفرض الثاني H2: يوجد تأثثر معنوي إيجابي للتوجيه المهني

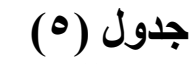

علي النواتج التنظيمية.

نتائج تحليل المسار للتأثيرات المباشرة للتوجيه المهني علي النواتج التنظيمية

\begin{tabular}{|c|c|c|c|c|}
\hline $\begin{array}{c}\text { المعنوية } \\
\text { P-Value }\end{array}$ & قيمة معامل & المتغير التابع & المتغير المستقل & الفرض \\
\hline$<0.001$ & 0.543 & التنظيمية & التوجيه المهني & H2 \\
\hline
\end{tabular}

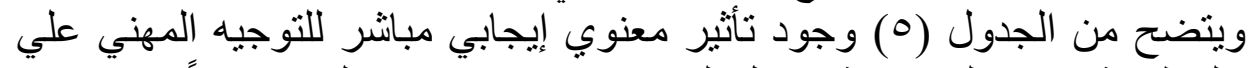

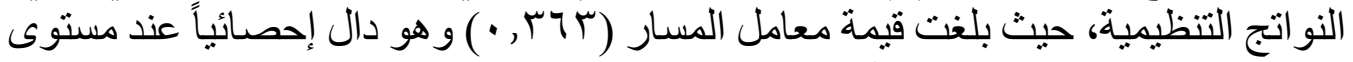

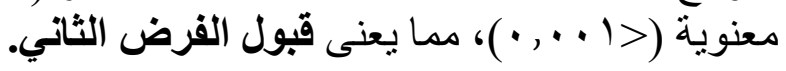


آ/ T/ T/ نتائج اختبار الفرض الثالث H3: يوجد تأثير معنوي إيجابي للتراحم الذاتي علي

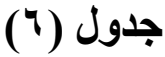

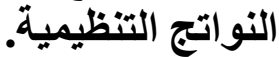

نتائج تحليل المسار للتأثيرات المباشرة للتراحم الذاتي علي النواتج التنظيمية

\begin{tabular}{|c|c|c|c|c|}
\hline $\begin{array}{c}\text { المعنوية } \\
\text { P-Value }\end{array}$ & قيمة معامل المسار & المتغير التابع & المتغير المستقل & الفرض \\
\hline$<0.001$ & 0.198 & التنظيمية & التراحم الذاتي & H3 \\
\hline
\end{tabular}

الهصدر: إعداد الباحثون اعتماداً على نتائج التحليل الإحصائي.

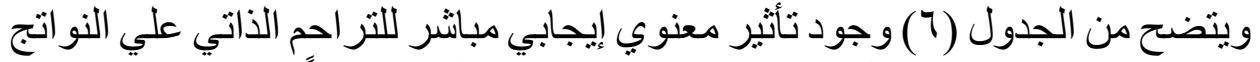

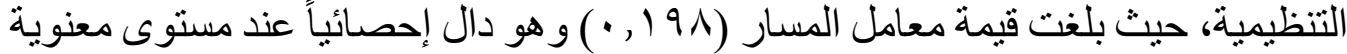

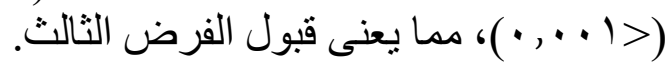

ب/ / / ـ ـ نتائج اختبار الفرض الرابع H4: يوجد تأثير معنوي غير مباثر للتوجيه المهني علي النواتج التنظيمية من خلال توسيط التراحم الذاتي.

(V) جدول

نتائج تحليل التأثيرات المباشرة وغير المباشرة والكلية للتوجيه المهني علي النواتج التنظيمية عند توسيط التراحم الأاتى نير

\begin{tabular}{|c|c|c|c|c|c|c|c|}
\hline $\begin{array}{l}\text { التحديد } \\
\text { Rعل } \\
\mathbf{R}^{2}\end{array}$ & المسار & المسبار غير & المباثــر & التتبعير & الوسنغير & المستفِّل & الفرض \\
\hline $42.1 \%$ & $0.615^{* * * *}$ & $0.072^{*}$ & $0.543^{* * *}$ & التنظيمئة & الأتراحي & التوجنيه & H4 \\
\hline عند (.0, ) & 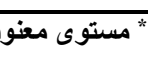 & & 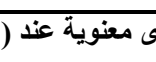 & (*t) & \multicolumn{3}{|c|}{ 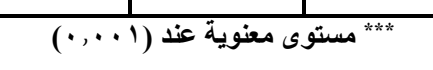 } \\
\hline
\end{tabular}

المصدر : إعداد الباحثون اعتماداً على نتائج التحليل الإحصائي. ويتضح من الجدول رقم (V) ما يلي:

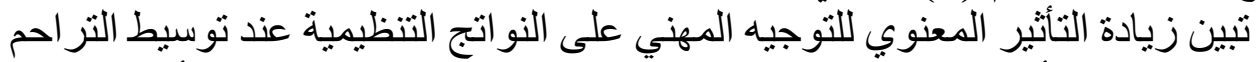

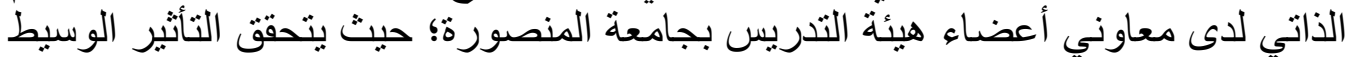
عندما يسنطيع متغير ما التأثير معنوياً على العلاقة بين متغيرين آخرين إما بتقوية هذه 
العلاقة أو إضعافها، وهو دال إحصائياً عند مستوى معنوية (Tr + • )، مما يعنى قبول

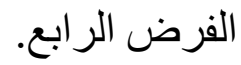

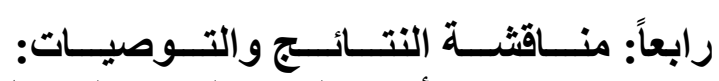

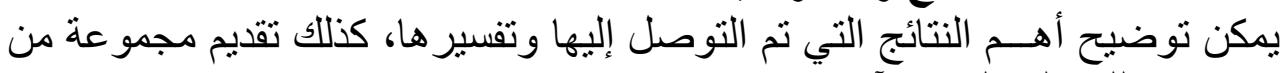

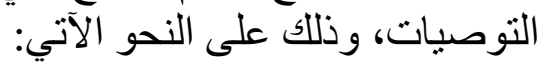

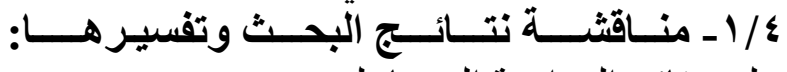

توصلت نتائج الدراسـة إلي ما يلي: الئي

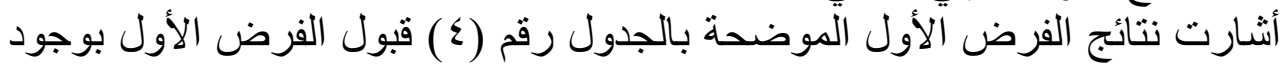

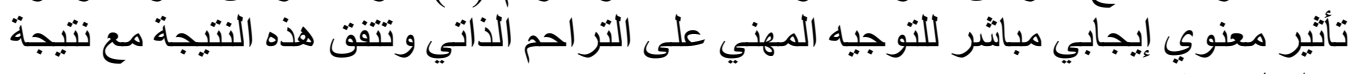

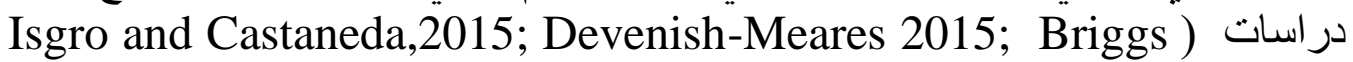

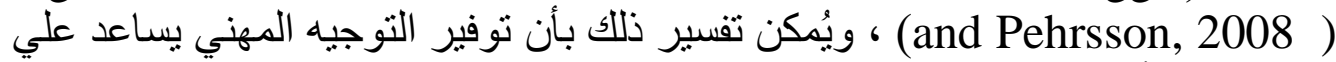

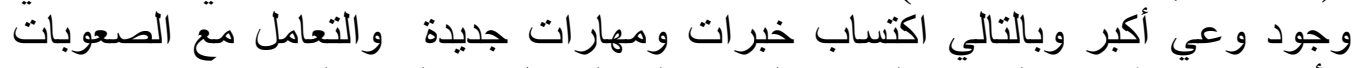

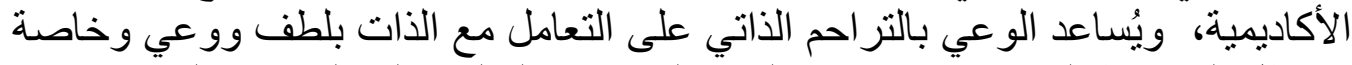

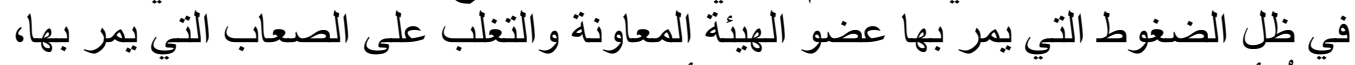

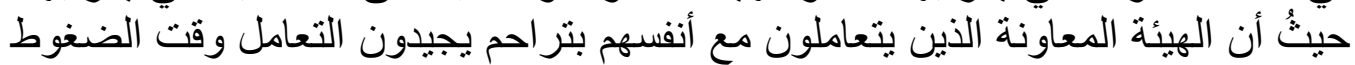

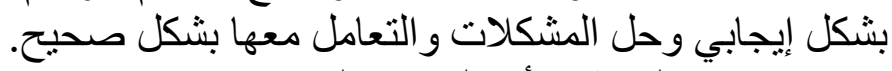

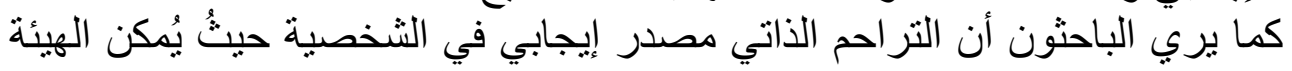

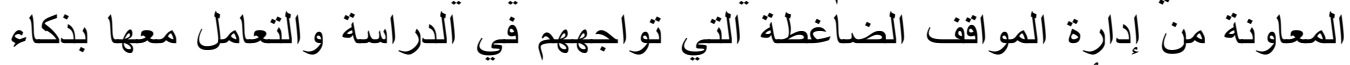

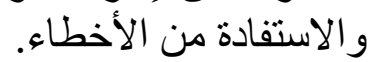

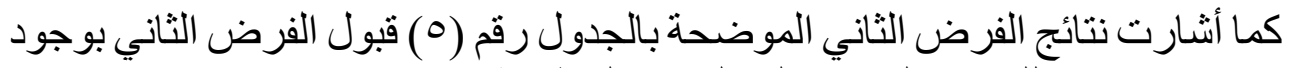

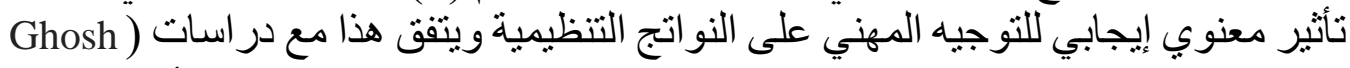
(and Reio ,2013; Craig et al., 2013; Kim et al. 2015; Arora, 2020)

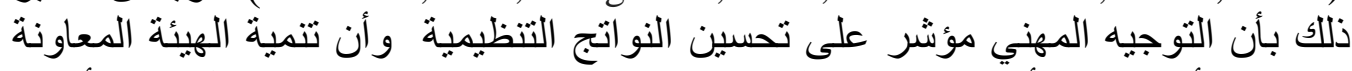

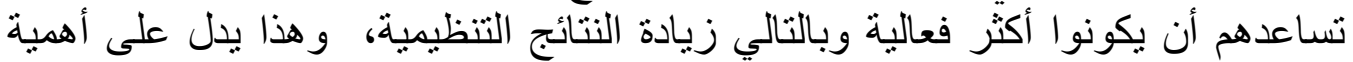

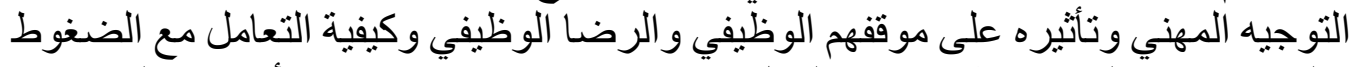

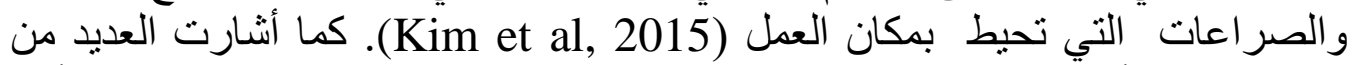

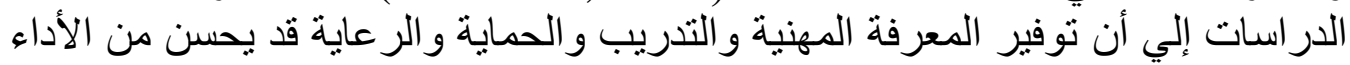

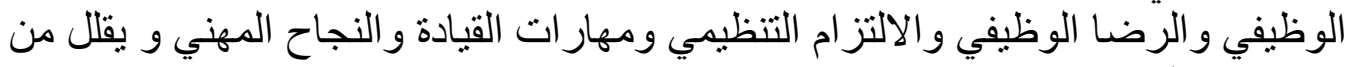

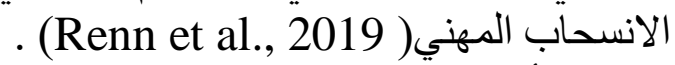

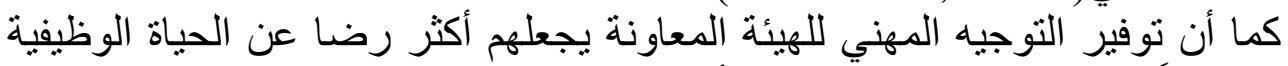
و أكثر التزماً وارتباطا بالنجاح المهني و الأداء التنظيمي (siengthai et al.,2020). 
كذللك توصلت نتائج الفرض الثالث الموضح بالجدول رقم (؟) قبول الفرض الثئي الثالث

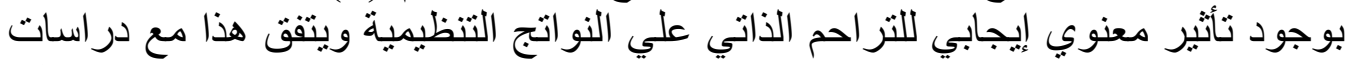

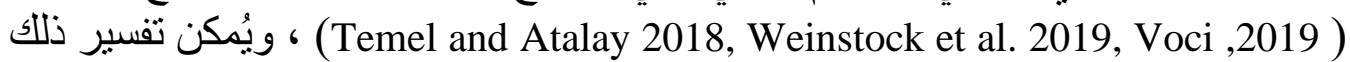

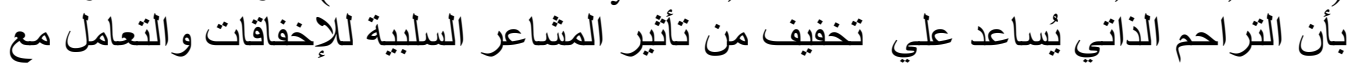

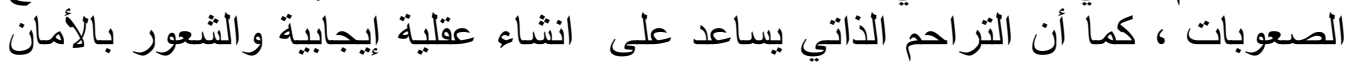

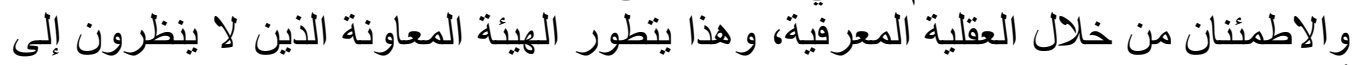

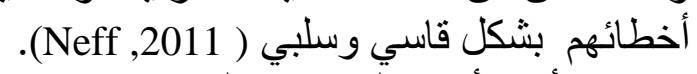

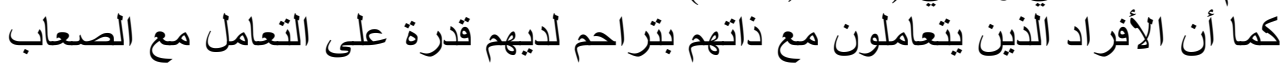

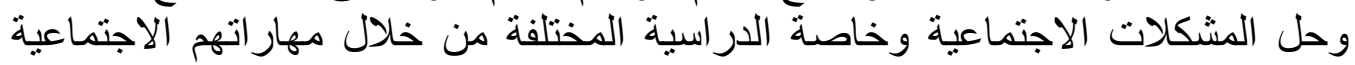

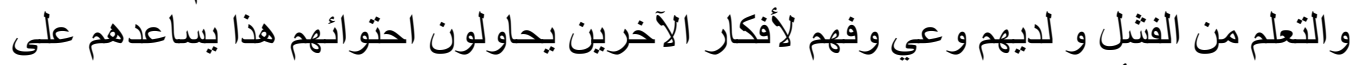

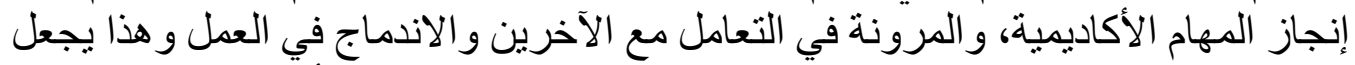

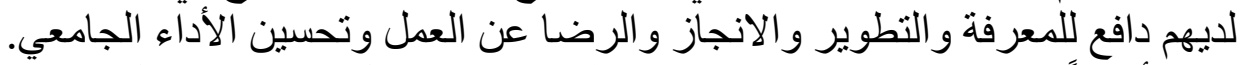

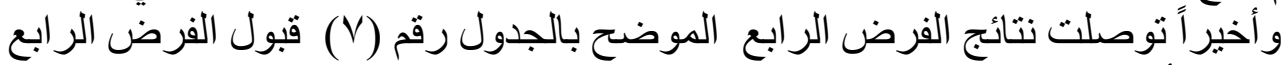

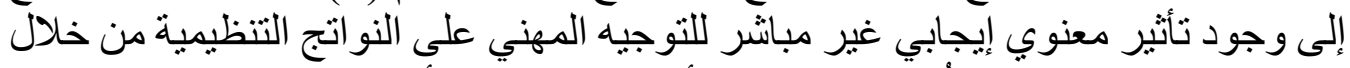

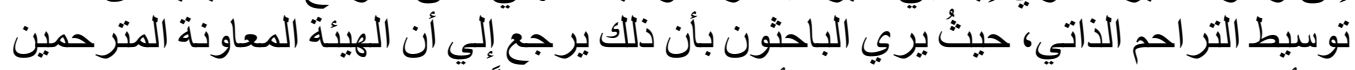

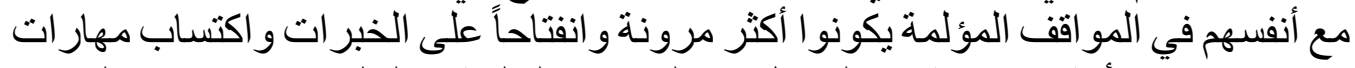

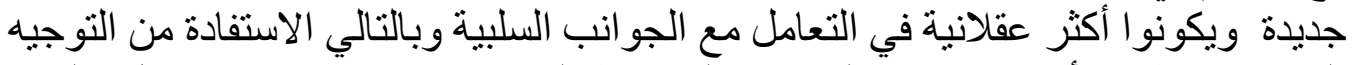

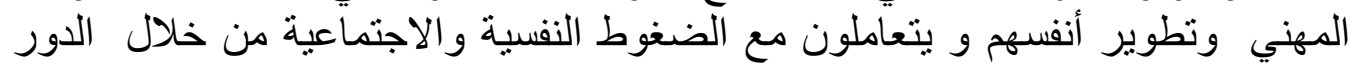

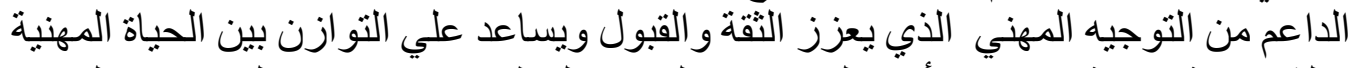

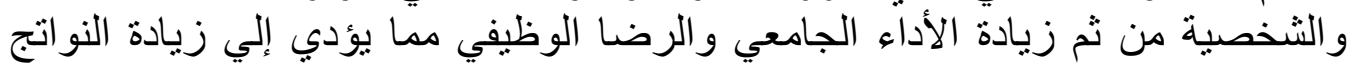

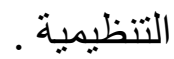

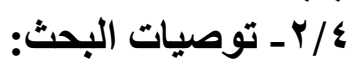

في ضوء النتائج التي تم التوصل إلتو إليها، و الاطلاع على نتائج عدد من الدر اسات السابقة

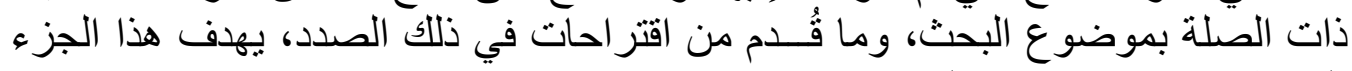

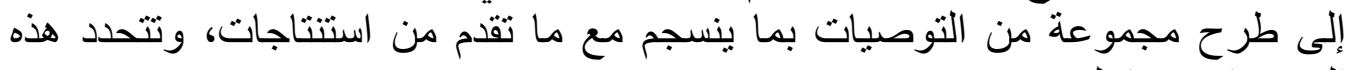
التوصيات فيما يلي:

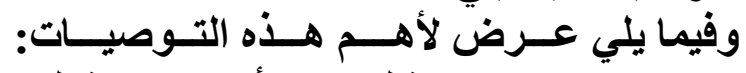

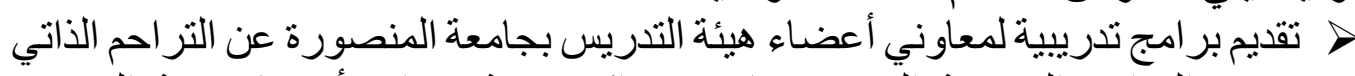

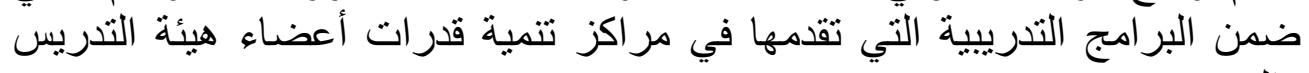
و والهي. > ز زيادة الو عي بأهية التعامل بتر احم مع الذات و التعامل بلطف و عدم الحكم عليها وخاص عند التعرض للضنغوط والصية الصعوبات بترات الجامعية. 


$$
\begin{aligned}
& \text { > بناء وتنمية شبكة من الاتصالات الفعالة داخل الجامعة لتدعم النمو الأكاديمي والمهني }
\end{aligned}
$$

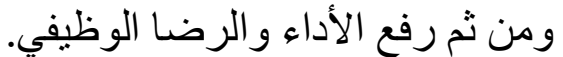

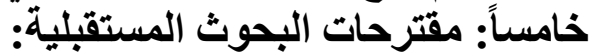

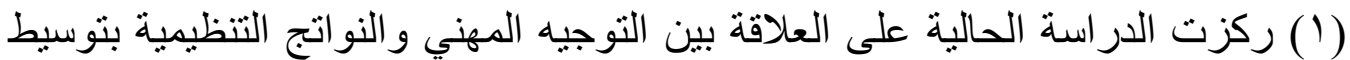

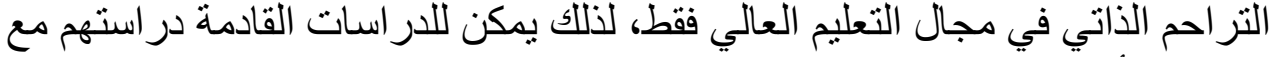

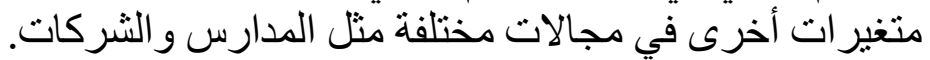

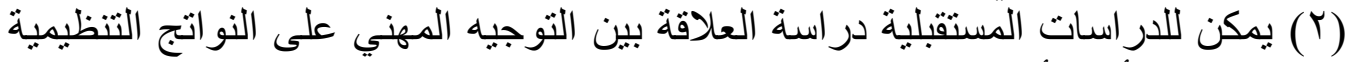

$$
\begin{aligned}
& \text { باستخدام أبعاد أخري للنو اتج التبن التظيمية. }
\end{aligned}
$$

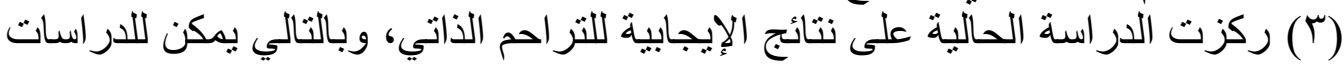

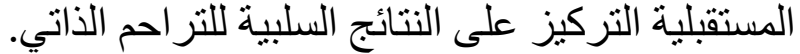

$$
\begin{aligned}
& \text { قائمة المراجع: - مبعة }
\end{aligned}
$$

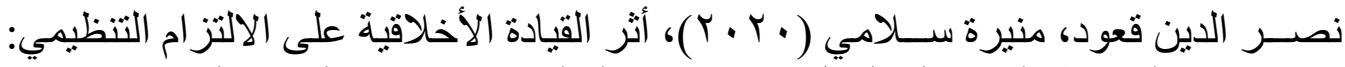

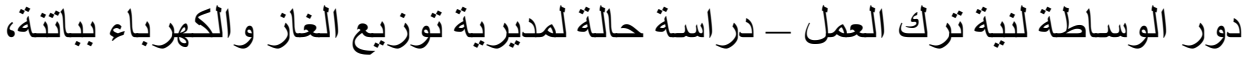

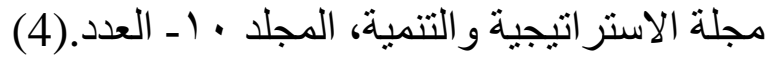

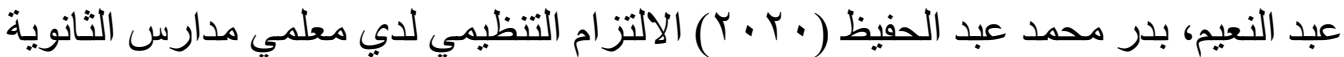

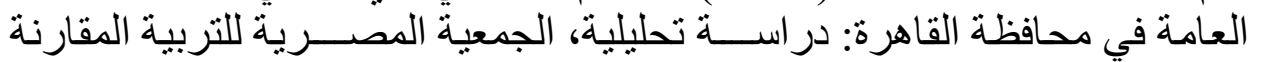

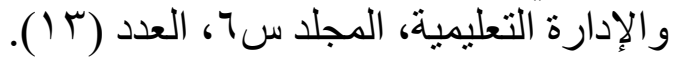

Al-Abedie, A. R. C., \& Al-Temini, A. H. A. (2015). The Mediating Effect of Organizational Happiness on The Relationship Between Benevolent Leadership and Organizational Outcomes: An Empirical Study at The University of Babylon. World Journal of Pharmaceutical Research, 4(09), 214-228.

Allen, N. J., \& Meyer, J. P. (1990). The measurement and antecedents of affective, continuance and normative commitment to the organization. Journal of occupational psychology, 63(1), 1-18.

Amemiya, R., \& Sakairi, Y. (2020). The role of self-compassion in athlete mindfulness and burnout: Examination of the effects of gender differences. Personality and Individual Differences, 166, 110167.

Amemiya, R., \& Sakairi, Y. (2020). The role of self-compassion in athlete mindfulness and burnout: Examination of the effects of gender differences. Personality and Individual Differences, 166, 110167.

Arora, R. (2020). Mediating role of mentoring functions on linking personality and occupational commitment in Indian organizations. Human Resource Development International, 1-26.

Barnard, L. K., \& Curry, J. F. (2011). Self-compassion: Conceptualizations, correlates, \& interventions. Review of general psychology, 15(4), 289-303. 
Block, M., \& Florczak, K. L. (2017). Mentoring: An evolving relationship. Nursing science quarterly, 30(2), 100-104.

Briggs, C. A., \& Pehrsson, D. E. (2008). Research mentorship in counselor education. Counselor Education and Supervision, 48(2), 101-113.

Chen, C., Wen, P., \& Hu, C. (2017). Role of formal mentoring in protégés' work-tofamily conflict: A double-edged sword. Journal of Vocational Behavior, 100, 101-110.

Coppin, R., \& Fisher, G. (2020). Career mentoring in aged care: Not all it seems. Australian Journal of Career Development, 29(1), 12-23.

Costa, J., Marôco, J., Pinto-Gouveia, J., Ferreira, C., \& Castilho, P. (2016). Validation of the psychometric properties of the Self-Compassion Scale. Testing the factorial validity and factorial invariance of the measure among borderline personality disorder, anxiety disorder, eating disorder and general populations. Clinical psychology \& psychotherapy, 23(5), 460-468.

Craig, C. A., Allen, M. W., Reid, M. F., Riemenschneider, C. K., \& Armstrong, D. J. (2013). The impact of career mentoring and psychosocial mentoring on affective organizational commitment, job involvement, and turnover intention. Administration \& Society, 45(8), 949-973.

Devenish-Meares, P. (2015). Call to compassionate self-care: Introducing selfcompassion into the workplace treatment process. Journal of Spirituality in Mental Health, 17(1), 75-87.

Diedericks, E., \& Rothmann, S. (2014). Flourishing of information technology professionals: Effects on individual and organisational outcomes. South African Journal of Business Management, 45(1), 27-41.

Dougherty, T. W., \& Dreher, G. F. (2007). Mentoring and career outcomes. The handbook of mentoring at work: Theory, research and practice, 51-93.

Felder, J. N., Lemon, E., Shea, K., Kripke, K., \& Dimidjian, S. (2016). Role of selfcompassion in psychological well-being among perinatal women. Archives of women's mental health, 19(4), 687-690.

Galili-Weinstock, L., Chen, R., Atzil-Slonim, D., Rafaeli, E., \& Peri, T. (2020). Enhancement of self compassion in psychotherapy: The role of therapists' interventions. Psychotherapy Research, 30(6), 815-828.

Germer, C. K., \& Neff, K. D. (2013). Self-compassion in clinical practice. Journal of clinical psychology, 69(8), 856-867.

Ghosh, R., \& Reio Jr, T. G. (2013). Career benefits associated with mentoring for mentors: A meta-analysis. Journal of Vocational Behavior, 83(1), 106-116.

Giancola, J. K., Van Groningen, A., Jansen, A. E., Chatterjee, A., Mulloy, L. L., Palmer, C., \& Lawson, M. A. (2020). Mentor vs. mentee perceptions of career 
mentoring partnerships and work outcomes: A multi-institutional study of faculty mentoring programs. MedEdPublish, 8.

Gilbert, P., \& Procter, S. (2006). Compassionate mind training for people with high shame and self-criticism: Overview and pilot study of a group therapy approach. Clinical Psychology \& Psychotherapy: An International Journal of Theory \& Practice, 13(6), 353-379.

Griffiths, K., Kopanidis, F., \& Steel, M. (2018). Investigating the value of a peer-topeer mentoring experience. Australasian marketing journal, 26(2), 92-98.

Hall, E. E., Walkington, H., Shanahan, J. O., Ackley, E., \& Stewart, K. A. (2018). Mentor perspectives on the place of undergraduate research mentoring in academic identity and career development: An analysis of award winning mentors. International Journal for Academic Development, 23(1), 15-27.

Hendrix, D., Born, D., \& Hopkins, D. (2015). Relationship of Transformational Leadership and Character With Five Organizational Outcomes. Journal of Character \& Leadership Integration, Spring.

Hwang, J., \& Hopkins, K. M. (2015). A structural equation model of the effects of diversity characteristics and inclusion on organizational outcomes in the child welfare workforce. Children and Youth Services Review, 50, 44-52.

Iacono, G. (2017). A call for self-compassion in social work education. Journal of Teaching in Social Work, 37(5), 454-476.

Isgro, K., \& Castañeda, M. (2015). Mothers in US academia: Insights from lived experiences. In Women's Studies International Forum (Vol. 53, pp. 174-181). Pergamon.

Jacobi, M. (1991). Mentoring and undergraduate academic success: A literature review. Review of educational research, 61(4), 505-532.

Jena, L. K., Pradhan, S., \& Panigrahy, N. P. (2018). Pursuit of organisational trust: Role of employee engagement, psychological well-being and transformational leadership. Asia Pacific Management Review, 23(3), 227-234.

Johlke, M. C., \& Duhan, D. F. (2015). Supervisor communication practices and service employee job outcomes. Journal of Service Research, 3(2), 154-165.

Kabat-Zinn, J. (2003). Mindfulness-based interventions in context: past, present, and future. Clinical psychology: Science and practice, 10(2), 144-156.

Kao, K. Y., Hsu, H. H., Lee, H. T., Cheng, Y. C., Dax, I., \& Hsieh, M. W. (2020). Career Mentoring and Job Content Plateaus: The Roles of Perceived Organizational Support and Emotional Exhaustion. Journal of Career Development. 
Kath, L. M., Magley, V. J., \& Marmet, M. (2010). The role of organizational trust in safety climate's influence on organizational outcomes. Accident Analysis \& Prevention, 42(5), 1488-1497.

Kedharnath, U. (2011). Influence of leaders' implicit followership theories on employee outcomes, The (Doctoral dissertation, Colorado State University).

Kim, K., \& Shin, T. H. (2019). Additive effects of performance-and commitmentoriented human resource management systems on organizational outcomes. Sustainability, 11(6), 1679.

Kim, S. S., Im, J., \& Hwang, J. (2015). The effects of mentoring on role stress, job attitude, and turnover intention in the hotel industry. International Journal of Hospitality Management, 48, 68-82.

Kim, S. S., Im, J., \& Hwang, J. (2015). The effects of mentoring on role stress, job attitude, and turnover intention in the hotel industry. International Journal of Hospitality Management, 48, 68-82.

Kraiger, K., Finkelstein, L. M., \& Varghese, L. S. (2019). Enacting effective mentoring behaviors: development and initial investigation of the cuboid of mentoring. Journal of Business and Psychology, 34(4), 403-424.

Kram, K. E., \& Isabella, L. A. (1985). Mentoring alternatives: The role of peer relationships in career development. Academy of management Journal, 28(1), $110-132$.

Kumar, P., \& Budhwar, P. (2020). Contextualizing mentoring in the Asian context. In Mentorship-driven Talent Management. Emerald Publishing Limited.

Kwahk, K. Y., \& Park, D. H. (2016). The effects of network sharing on knowledgesharing activities and job performance in enterprise social media environments. Computers in Human Behavior, 55, 826-839.

Leck, J., \& Orser, B. (2013). Fostering trust in mentoring relationships: An exploratory study. Equality, diversity and inclusion: An international journal.

Lo, M. C., \& Ramayah, T. (2011). Mentoring and job satisfaction in Malaysian SMEs. Journal of management development.

López, A., Sanderman, R., Ranchor, A. V., \& Schroevers, M. J. (2018). Compassion for others and self-compassion: levels, correlates, and relationship with psychological well-being. Mindfulness, 9(1), 325-331.

MacBeth, A., \& Gumley, A. (2012). Exploring compassion: A meta-analysis of the association between self-compassion and psychopathology. Clinical psychology review, 32(6), 545-552.

Narzary, G., \& Palo, S. (2020). Structural empowerment and organisational citizenship behaviour. Personnel Review. 
Neff, K. D. (2003b). The development and validation of a scale to measure selfcompassion. Self and identity, 2(3), 223-250.

Neff, K. D. (2011). Self-compassion, self-esteem, and well-being. Social and personality psychology compass, 5(1), 1-12.

Neff, K. D., \& Beretvas, S. N. (2013). The role of self-compassion in romantic relationships. Self and Identity, 12(1), 78-98.

Neff, K. D., \& Vonk, R. (2009). Self-compassion versus global self-esteem: Two different ways of relating to oneself. Journal of personality, 77(1), 23-50.

Neff, K. D., Hsieh, Y. P., \& Dejitterat, K. (2005). Self-compassion, achievement goals, and coping with academic failure. Self and identity, 4(3), 263-287.

Neff, K.D, Knox M.C., (2017). Self-compassion. Department of Educational Psychology, The University of Texas at Austin, Austin , TX, USA, Springer International Publishing. , Encyclopedia of Personality and Individual Differences.

Neff, K.D. (2003a). Self-compassion: An alternative conceptualization of a healthy attitude toward oneself. Self and Identity, 2 (2), 85-102.

Nguyen, C., \& Duong, A. (2020). The Impact of Training and Development, Job Satisfaction and Job Performance on Young Employee Retention. International Journal of Future Generation Communication and Networking, 13(3), 373386.

Noe, R. A. (1988). An investigation of the determinants of successful assigned mentoring relationships. Personnel psychology, 41(3), 457-479.

Phillips, W. J. (2018). Future-outlook mediates the association between selfcompassion and well-being. Personality and Individual Differences, 135, 143148.

Proeve, M., Anton, R., \& Kenny, M. (2018). Effects of mindfulness-based cognitive therapy on shame, self-compassion and psychological distress in anxious and depressed patients: A pilot study. Psychology and Psychotherapy: Theory, Research and Practice, 91(4), 434-449.

Raes, F., Pommier, E., Neff, K. D., \& Van Gucht, D. (2011). Construction and factorial validation of a short form of the self-compassion scale. Clinical psychology \& psychotherapy, 18(3), 250-255.

Ragins, B. R., \& McFarlin, D. B. (1990). Perceptions of mentor roles in cross-gender mentoring relationships. Journal of Vocational Behavior, 37(3), 321-339.

Renn, R. W., Steinbauer, R., \& Huning, T. M. (2019). External career mentoring and mentor turnover intentions: Role of mentor work engagement, satisfaction with protégé, and meeting frequency. In Evidence-based HRM: a Global Forum for Empirical Scholarship. Emerald Publishing Limited. 
Rod, M., \& Ashill, N. J. (2010). The effect of customer orientation on frontline employees job outcomes in a new public management context. Marketing Intelligence \& Planning.

Samad, A. (2015). Towards an understanding of the effect of leadership on employee wellbeing and organizational outcomes in Australian universities. The Journal of Developing Areas, 49(6), 441-448.

Sellers, K., Amatullah, T., \& Malin, J. R. (2021). Learning to level up: personal narratives about mentoring for the professoriate during a crisis. International Journal of Mentoring and Coaching in Education.

Siengthai, S., Pila-Ngarm, P., \& Sorakraikitikul, M. (2020). How Mentors and Protégés Perceive and Practice mentoring in Thailand. In Mentorship-driven Talent Management. Emerald Publishing Limited.

Siengthai, S., Pila-Ngarm, P., \& Sorakraikitikul, M. (2020). How Mentors and Protégés Perceive and Practice mentoring in Thailand. In Mentorship-driven Talent Management. Emerald Publishing Limited.

Simha, A., \& Cullen, J. B. (2012). Ethical climates and their effects on organizational outcomes: Implications from the past and prophecies for the future. Academy of Management Perspectives, 26(4), 20-34.

Snyder, J. L., \& Cistulli, M. D. (2018). Application of In-Group Identification to Organizations: A Study of the Impact of Self-Investment and Self-Definition on Key Organizational Outcomes. International Journal of Business Communication.

Snyder, J. L., \& Cistulli, M. D. (2018). Application of In-Group Identification to Organizations: A Study of the Impact of Self-Investment and Self-Definition on Key Organizational Outcomes. International Journal of Business Communication.

Solomon, C., \& Barden, S. M. (2016). Self-compassion: A mentorship framework for counselor educator mothers. Counselor Education and Supervision, 55(2), 137-149.

sriviboon, c. (2020). impact of selected factors on job performance of employees in it sector: a case study of indonesia. journal of security \& sustainability issues, 9.

Sun, X., Chan, D. W., \& Chan, L. K. (2016). Self-compassion and psychological wellbeing among adolescents in Hong Kong: Exploring gender differences. Personality and Individual Differences, 101, 288-292.

Temel, M., \& Atalay, A. A. (2018). The relationship between perceived maternal parenting and psychological distress: Mediator role of celf-compassion. Current Psychology, 18 . 
Umar, T. R., Yammama, B. A., \& Shaibu, R. O. (2020). The Implications of Adopting and Implementing Electronic Human Resource Management Practices on Job Performance. Journal of Human Resource Management, 8(2), 96-108.

Van Vianen, A. E., Rosenauer, D., Homan, A. C., Horstmeier, C. A., \& Voelpel, S. C. (2018). Career mentoring in context: A multilevel study on differentiated career mentoring and career mentoring climate. Human Resource Management, 57(2), 583-599.

Voci, A., Veneziani, C. A., \& Fuochi, G. (2019). Relating mindfulness, heartfulness, and psychological well-being: the role of self-compassion and gratitude. Mindfulness, 10(2), 339-351.

Weinberg, F. J. (2019). How and when is role modeling effective? The influence of mentee professional identity on mentoring dynamics and personal learning outcomes. Group \& Organization Management, 44(2), 425-477.

Wu, Q., Chi, P., Zeng, X., Lin, X., \& Du, H. (2019). Roles of Anger and Rumination in the Relationship Between Self-Compassion and Forgiveness. Mindfulness, 10(2), 272-278.

Wu, Q., Chi, P., Zeng, X., Lin, X., \& Du, H. (2019). Roles of Anger and Rumination in the Relationship Between Self-Compassion and Forgiveness. Mindfulness, 10(2), 272-278.

Zainal, N., Zawawi, D., Aziz, Y. A., \& Ali, M. H. (2020). Work-Family Conflict and Job Performance: Moderating Effect of Social Support among Employees in Malaysian Service Sector. International Journal of Business and Society, 21(1), 79-95.

Zessin, U., Dickhäuser, O., \& Garbade, S. (2015). The relationship between selfcompassion and well-being: A meta-analysis. Applied Psychology: Health and Well-Being, 7(3), 340-364. 